\title{
Time-varying volatility, default and the sovereign risk premium
}

\author{
Hernán D. Seoane* \\ Universidad Carlos III de Madrid
}

July 17, 2015

\begin{abstract}
This paper studies how changes in the volatility of aggregate income affect sovereign spreads. I document a positive correlation between sovereign spreads and aggregate income volatility for a set of European economies. Then, I propose an endogenous sovereign spread model with time-varying volatility to understand this fact. Volatility changes affect savings and the sovereign spread. However, the impact of volatility shocks is state dependent, when the economy is relatively rich an increase in volatility is prone to generate precautionary savings. Instead, when the economy is relatively poor, an increase in volatility is likely to induce an increase in foreign debt and a higher spread. This mechanism is absent in standard business cycle models and only appears because of the default option. Moreover, this mechanism can generate a substantial variability of spreads only due to volatility shocks. In this way, the model is able to rationalize the positive correlation between sovereign spreads and volatility observed in the data.
\end{abstract}

Keywords: Default, Sovereign Risk Premium, Stochastic Volatility, Uncertainty Shocks.

JEL Classification: E21, E32, F34, F41.

*Department of Economics, Universidad Carlos III de Madrid, Calle Madrid 126, 28903 Getafe, Madrid, Spain. Tel.: +34 91624 5744. E-mail address: hseoane@eco.uc3m.es. I thank Jonas Arias, Antonia Diaz, Andrés Erosa, Angelo Fasolo, Enrique Kawamura, Sandra Lizarazo, Bela Szemely, Abderrahim Taamouti and the participants of several Conferences, Workshops and Seminars. I would like to thank Jesús Fernández-Villaverde and two anonymous referees for comments and suggestions and I thank Javier Garcia-Cicco for sharing his codes for estimation of Stochastic Volatility models. The usual disclaimers apply. 


\section{Introduction}

This paper studies how changes in the volatility of aggregate income affect the savings decisions and sovereign bond spreads of small open economies where the sovereign interest rate reflects endogenous default incentives. This paper argues that the impact of an increase in the volatility of income appears even if the income level of the small open economy remains constant. Moreover, volatility shocks have a state dependent impact on the spreads given then existence of precautionary savings motive and the existence of limited liability from the default option.

I first document that economies that suffer strong variability of sovereign spreads also experience increase in aggregate income volatility. I show this by estimating stochastic volatility models for Southern European economies greatly affected by the 2008 debt crisis. Moreover, I show that this is robust to other volatility measures (stock market volatility) and for a greater sample of countries during times of financial turbulence. Then, I develop a dynamic stochastic general equilibrium model with stochastic volatility that produces an endogenous sovereign spread, as in Eaton and Gersovitz (1981) and Arellano (2008). Feeding the estimates of income stochastic volatility processes, I calibrate four versions of the model to match the experiences of Greece, Italy, Portugal and Spain. I find that an increase in the volatility of output has asymmetric impact on endogenous variables depending on the income and level of debt. When the economy is relatively rich, situation associated to a nil default probability, an increase in volatility triggers a precautionary savings behavior that tends to increase savings. On the other hand, increasing the volatility of output when the economy experiences a large default probability, that is when debt is high or income is low, can actually reduce savings.

The intuition for these findings is simple: when the economy is relatively rich, default probability is zero and the value of the default option is nil, hence, the economy behaves in a similar way to an economy without default option and the precautionary savings motive drives the dynamics after a volatility shock. Hence, an increase in volatility together with a third order positive derivative of the utility function imply that savings increase. Conversely, when the economy is relatively poor the default option becomes more attractive. In this case, an increase in volatility, that has a symmetric impact on the two tails of income probability distribution, works in a different way. The government realizes that high volatility increases the probability of a very high income realization and, if this happens, the economy would like to experience a high consumption increase in the future. On the other hand, an increase in volatility also increases the probability of a very low income realization, in which case the economy would be able to 
ameliorate the consumption drop by defaulting. Hence, depending on the size of the increase in volatility and default incentives, the government might actually increase debt today in order to take advantage of the probability of a large output in the future, given that the limited liability implies that the economy will not face all the losses of a very bad income realization. Risk neutral international investors, in turn, are willing to finance such a behavior as long as they break even in expectation.

Then, I inquire what are the effects of volatility changes in the average and variability of sovereign spreads as well as in other moments of interest. To do this, I implement a variance decomposition exercise as in Fernandez-Villaverde et al. (2011), that is, I simulate the economy shutting down one source of variability at a time. I find that if the economy is only affected by income level shocks, default probabilities and the mean and standard deviation of the spreads can substantially change. Moreover, I find that volatility shocks alone, in the absence of any shock to the level of income, can generate substantial variability in sovereign spreads. This finding suggests that the theoretical implications of the model can be quantitatively relevant.

This paper provides some novel insights for the understanding of savings and consumption decision under uncertainty. To my best knowledge, this paper is the first one to study the impact of volatility shocks on savings when default can happen in equilibrium and in documenting the state dependent impact of volatility on the savings decision, an effect that is not observed in standard small open economy models with full commitment. ${ }^{1}$ Additionally, it contributes to inquire about the impact of uncertainty changes in the dynamics of sovereign spread and to highlight the economic behavior behind the positive correlation between spreads and volatility, namely the fact that increases in volatility might induce an increase in debt because of the default option.

On the other hand, this paper does not provide a theory of volatility changes. This is in line with the majority of the papers in the literature on time varying volatility such as Justiniano and Primiceri (2008), Bloom (2009) and Fernandez-Villaverde et al. (2011). Moreover, as discussed in Fernandez-Villaverde et al. (2011), this assumption is in line with the tradition in macroeconomics that considers key variables as exogenous in order to study and "measure" their impact in business cycle dynamics. The reason for assuming exogenous volatility shocks is to focus on the economic mechanism that transmits volatility shocks into spread variability. Moreover and importantly, there is no accepted theory of endogenous volatility changes and introducing it together with the current analysis will make the point of this paper

\footnotetext{
${ }^{1}$ Consider for instance the "Debt Elastic Interest Rate Model" (DEIR) as in Schmitt-Grohe and Uribe (2003). Here, an increase in volatility would trigger an increase in precautionary savings that would decrease interest rate spread, which implies a negative (and counterfactual) correlation between volatility and spreads. That is, the results of standard RBC small open economy with full commitment and DEIR closing device implies that volatility and spreads are negatively correlated.
} 
less clean. Additionally, the theoretical model assumes that agents in the model know the stochastic process of volatility and observes its realization. This is also done to keep to objective of this paper as clean as possible, introducing a learning scheme about volatility shocks complicates the analysis although it is certainly an interesting extension for future research.

\section{Related Literature}

This paper is related to the seminal paper by Eaton and Gersovitz (1981) on sovereign risk premium and default that models strategic default. In the same line, Arellano (2008) discuss and apply a model in the same spirit to understand the macroeconomic behavior of Argentina during 2002 default and show that under asymmetric output losses, default occurs during bad times. Aguiar and Gopinath (2006) studies the impact of permanent shocks and the default decisions. Lizarazo (2012) extends this framework to account for risk aversion of international lenders. Yue (2010), on the other hand, studies the default decisions under debt renegotiation. An optimal policy approach is taken by Cuadra and Sapriza (2008) who model the default decision for a government that has access to distortionary taxation. More recently, Mendoza and Yue (2012) study the default decision with endogenous output in order to reconcile the stylized facts of default episodes and the business cycle. This literature, however, has not studied the impact of volatility shocks in spreads.

This paper is also related to the literature on uncertainty and volatility shocks, such as Justiniano and Primiceri (2008), Bloom (2009) and Bloom et al. (2007), among many others, that uses general and partial equilibrium models to study the effect of changes in the volatility of technology shocks in general equilibrium models for closed economies. These papers, however, do not study the role of volatility shocks in accounting for the variability of an endogenous sovereign risk premium. Additionally, my paper is closely related to Fernandez-Villaverde et al. (2011) and Gruss and Mertens (2009) that study the effect of changes in the volatility of risk premium shocks in macroeconomic dynamics. The authors, however, take the sovereign spread as exogenously determined and study the way changes in the volatility of risk premium shocks affect the macroeconomic performance of small open economies. In contrast, my paper studies the effect of changes in the volatility of the income process on the endogenous sovereign risk premium. Hence, I consider this paper is a complement to theirs.

Even though there is an extensive literature that studies sovereign spread dynamics, there is no agreement on the factors driving this variable. One strand of the literature finds evidence suggesting that the sovereign risk premium is exogenously determined, or at least a large part of it does not depend on 
domestic conditions. In this line we can find Uribe and Yue (2006) and Longstaff et al. (2011). On the other hand, Cline (2004), Cantor and Packer (1996), Eichengreen and Mody (2000), among many other references, find that a large share of sovereign spread variability depends on domestic factors. I contribute to this literature by considering the role of volatility in a structural model of endogenous spreads.

\section{Default and volatility}

Figure 1 provides suggestive evidence about the importance of considering volatility changes when sovereign spreads rise.
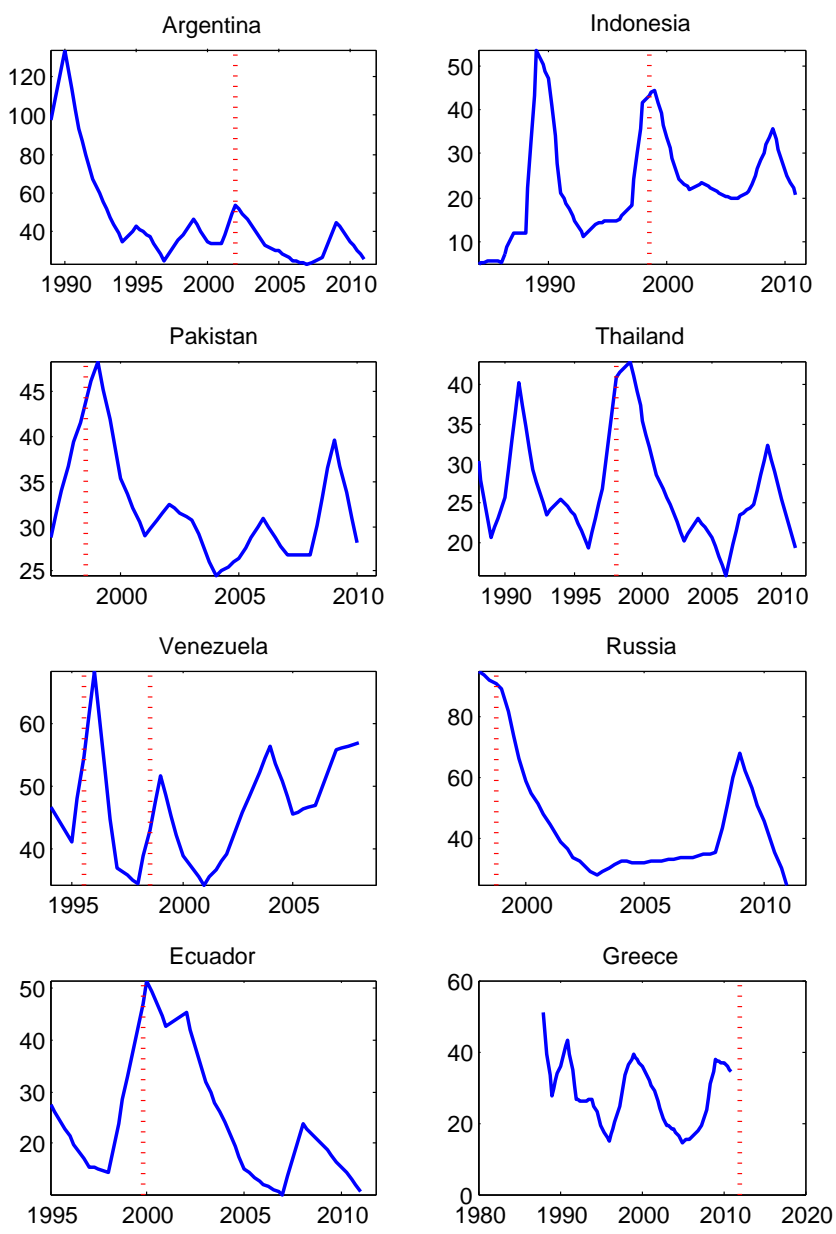

Figure 1: Stock market volatility and default episodes

Note: This figure plots stock market volatility in blue lines together with the recent default episodes in dashed red lines. Stock Market Volatility is from Global Financial Development data set from The World Bank, originally at annual frequencies interpolated to quarterly frequency. Default dates for all countries except Greece are from Mendoza and Yue (2012).

The figure presents the stock market volatility for several countries that experienced default episodes 
in the last 20 years. As seen in the figure, in all the cases, volatility starts to rise at least 1 year before the default episode and remains persistently higher for about two years after the beginning of default. In the bottom right panel I plot the stock market volatility for Greece for the period 1988 to 2011 (last year in sample) and the 2012 default/debt restructuring episode. As can be seen in the figure, Greece's stock market volatility continuously increases since 2005. Of course, this figure is not intended to suggest causality but it provides suggestive evidence that default usually occurs during periods of high uncertainty and, consequently, uncertainty might play a role in default episodes and might matter for the pricing of sovereign bonds.

The remainder of the paper proceeds as follows. Section 2, presents and estimates a stochastic volatility model for the exogenous output process. Section 3 presents the model for the endogenous sovereign risk premium in the spirit of Eaton and Gersovitz (1981) and Arellano (2008), augmented with stochastic volatility. Section 4, discusses the strategy to calibrate and parametrize the models for each economy. Section 5 discusses the main findings of the paper including policy functions and study of the dynamics conditional on no defaulting. Section 6 presents two extensions, one with risk averse lenders and one with endogenous output. Finally, section 7 concludes. $^{2}$

\section{A model for output with stochastic volatility}

This section derives stylized facts on sovereign spreads and macroeconomic volatility. I proxy the unobserved volatility by the time-varying volatility of income which I estimate using by the following model,

$$
\begin{gathered}
\tilde{y}_{t}=\rho \tilde{y}_{t-1}+\exp \left\{\sigma_{t}\right\} \epsilon_{t}, \\
\sigma_{t}=\left(1-\rho_{\sigma}\right) \bar{\sigma}+\rho_{\sigma} \sigma_{t-1}+\eta \epsilon_{\sigma, t} .
\end{gathered}
$$

Here, $\tilde{y}_{t}$ denotes the logarithm of cubic detrended and demeaned output; and $\sigma_{t}$ denotes the logarithm of standard deviation that evolves accordingly to equation (2). I assume $\bar{\sigma}$ is the average of the logarithm of the standard deviation, $\eta$ is a positive constant and the processes are mean reverting.

As seen from equations (1) and (2), $\epsilon_{t}$ and $\epsilon_{\sigma, t}$ affect output level and volatility, respectively. Given this setup, an innovation to output, $\hat{\epsilon}_{t}$, has a different impact conditional on the realization of the volatility shock, $\epsilon_{\sigma, t}$. In particular, a high $\epsilon_{\sigma, t}$ amplifies $\hat{\epsilon}_{t}$ which, contemporaneously, induces a larger change on

\footnotetext{
${ }^{2}$ An online appendix describes the data treatment and data sources, provides details on the estimation strategy and on the solution method. The appendix can be found in http://www.eco.uc3m.es/ hseoane/research.html.
} 
output. ${ }^{3}$

The interpretation of a volatility shock is straightforward but not unique. Here, I interpret higher income volatility as higher risk regarding the realization of the income shock. Given that volatility is modeled as a persistent process, an increase in volatility today implies that future income realizations are (correctly) perceived as more volatile. ${ }^{4}$

Table 1: Prior Distributions

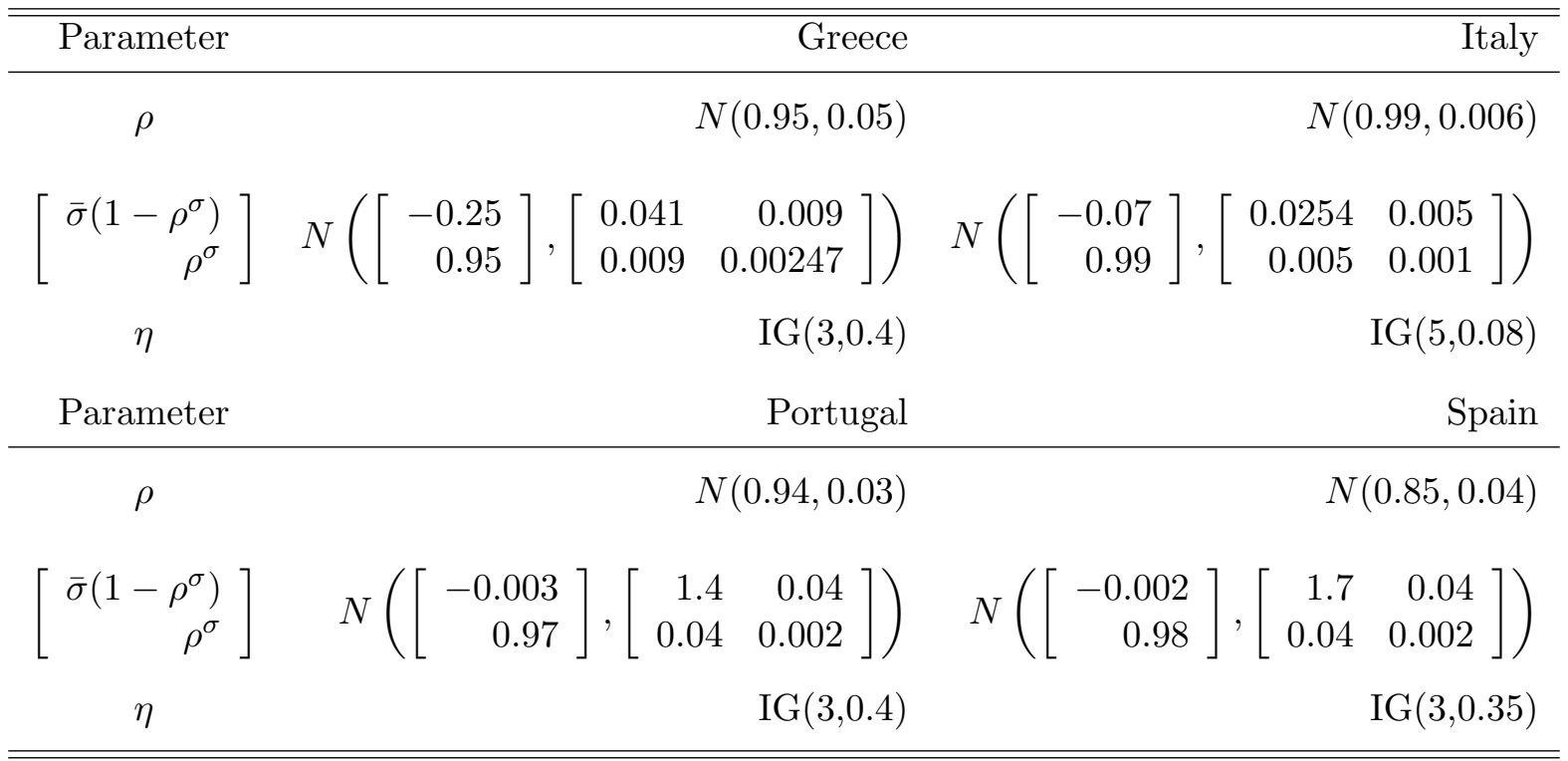

Note: $N(x, y)$ denotes a Normal distribution with mean $x$ standard deviation $y$. The priors for autocorrelation coefficients are truncated normal in the interval $(0,0.995) . I G(x, y)$ denotes an Inverse Gamma distribution with degrees of freedom $x$ and scale matrix $y$.

The stochastic volatility model is highly non-linear and its estimation is challenging. This paper follows Kim et al. (1998) and Garcia Cicco et al. (2012) strategy and implements an Importance Sampling within a Gibbs Sampling. Table 1 presents the prior distributions, I assume conjugate priors, Normal priors for $\rho, \bar{\sigma}$ and $\rho_{\sigma}$; and Inverse Gamma prior for $\eta .^{5}$

I use data from 1970Q1 to 2014Q2. Table 2 presents the posterior estimates and the 16th and

\footnotetext{
${ }^{3}$ The stochastic volatility model provides a convenient measure of time-varying volatility for macroeconomic models given that output data is usually collected at quarterly frequencies, alternative models such as "realized volatility" models are usually used with intra-day data. On the other hand, this stochastic volatility model is parsimonious but able to account for complex dynamics. Moreover, for the interest of this paper stochastic volatility model is a more convenient approach than that of the Generalized Autoregressive Conditional Heteroskedasticity model (GARCH) given that using stochastic volatility model we can isolate the impact of two different shocks, one to the level of output and one to the volatility of output whereas in the GARCH model we only have a shock to the level of output.

${ }^{4}$ Note that this interpretation is standard in the time-varying stochastic volatility literature, as can be seen in FernandezVillaverde et al. (2011).

${ }^{5}$ Qualitatively similar results are obtained using a Particle Filter. This alternative procedure does not need conjugate priors, but leads to wider credible sets.
} 
Table 2: Posterior estimates

\begin{tabular}{|c|c|c|c|}
\hline Parameter & Posterior Median & 16th Percentile & 84th Percentile \\
\hline \multicolumn{4}{|c|}{ Greece } \\
\hline $\bar{\sigma}$ & -4 & -4.4 & -3.7 \\
\hline$\rho$ & 0.98 & 0.97 & 0.99 \\
\hline$\rho^{\sigma}$ & 0.94 & 0.91 & 0.96 \\
\hline$\eta$ & 0.26 & 0.22 & 0.31 \\
\hline \multicolumn{4}{|c|}{ Italy } \\
\hline $\bar{\sigma}$ & -5.1 & -5.4 & -4.9 \\
\hline$\rho$ & 0.97 & 0.96 & 0.99 \\
\hline$\rho^{\sigma}$ & 0.94 & 0.92 & 0.97 \\
\hline$\eta$ & 0.2 & 0.17 & 0.25 \\
\hline \multicolumn{4}{|c|}{ Portugal } \\
\hline $\bar{\sigma}$ & -4.6 & -4.9 & -4.4 \\
\hline$\rho$ & 0.98 & 0.96 & 0.99 \\
\hline$\rho^{\sigma}$ & 0.92 & 0.89 & 0.95 \\
\hline$\eta$ & 0.29 & 0.24 & 0.35 \\
\hline \multicolumn{4}{|c|}{ Spain } \\
\hline $\bar{\sigma}$ & -4.9 & -5.1 & -4.6 \\
\hline$\rho$ & 0.99 & 0.99 & 0.99 \\
\hline$\rho^{\sigma}$ & 0.93 & 0.9 & 0.96 \\
\hline$\eta$ & 0.23 & 0.19 & 0.26 \\
\hline
\end{tabular}

Note: Posterior medians, 16 th and 84th percentiles drawn from the last half of 25,000 Gibbs Sampling replications.

84th percentiles. As seen in the table, there is a strong autocorrelation in output level and slightly milder for volatilities. Additionally, the standard deviation of volatility shocks, range from 0.2 to 0.3 , these magnitudes imply that in these cases a one standard deviation shock to volatility increases income volatility substantially, in the range of 20 to $30 \%$.

Using the point estimates in Table 2 and the realizations of the volatility innovations, it is possible to recover the smoothed estimates of the volatility process. Figure 2, plots the stochastic volatility jointly with the $60 \%$ credible bands.

As seen in the figure, although there is substantial uncertainty on the actual volatility level, changes in the volatility of output are significant for all economies and large changes are observed during the recent crisis. It is important to say that, even in this case, we cannot rule out that volatility has remained constant for several periods, such as the period between 1975-1985 or mid 1990s for Greece or the early 

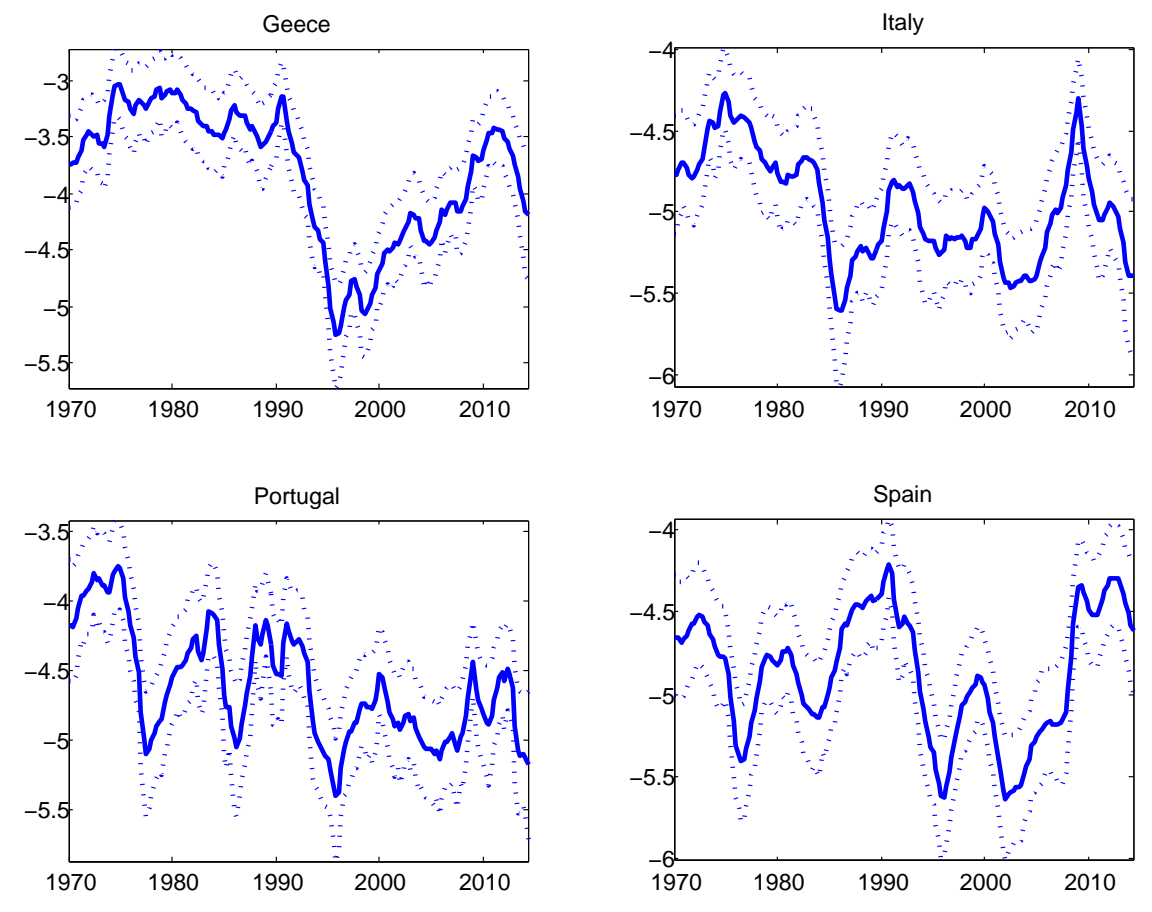

Figure 2: Stochastic volatility

Note: This figure plots the smoothed estimates of the stochastic volatility implied by our model (in solid lines) together with credible bands corresponding to 1 standard deviation (in dotted lines).

2000s for Portugal. However, we can identify a substantial contraction in volatility during the 1990-2000 period, and a large increase in volatility after 2006 in all the cases. Figure 3 plots the volatility of output and the sovereign spreads. ${ }^{6}$

As seen in the figure, there seems to be an overall strong positive correlation between the volatility and the sovereign spread over the period 2001-2012 for all the countries. This correlation is generated by the rapid drop in uncertainty and spreads since the beginning of the monetary union and the increase in both measures after 2008. Table 3 presents related evidence, the point estimates and standard errors of the correlations between output and sovereign risk premium, and volatility and sovereign spreads.

As seen in the table, output and sovereign spreads have been negatively correlated in these economies for the last 14 years. On the other hand, the volatility of output and the sovereign spreads are positively correlated. An important feature of these series is the persistence of both volatility and sovereign risk

\footnotetext{
${ }^{6}$ The measure of sovereign spread is the difference between the real interest rate on long term sovereign bonds and the real return of German long term bonds. Raw data on interest rates are "Long Term Interest Rates" from European Central Bank with maturities of 10 years, issued in Euros. In order to compute real interest rates, expected inflation has to be subtracted from nominal rates. Usually, expected inflation are computed by averaging previous periods inflation. Here, I assume expected inflation is the same across countries, which is a reasonable assumption given that all of these economies share the same monetary policy rule and the same Central Bank. However, as a robustness, I compute real rates by subtracting the average of previous 4 quarters of HCPI inflation from Eurostat and the findings of this section remain.
} 

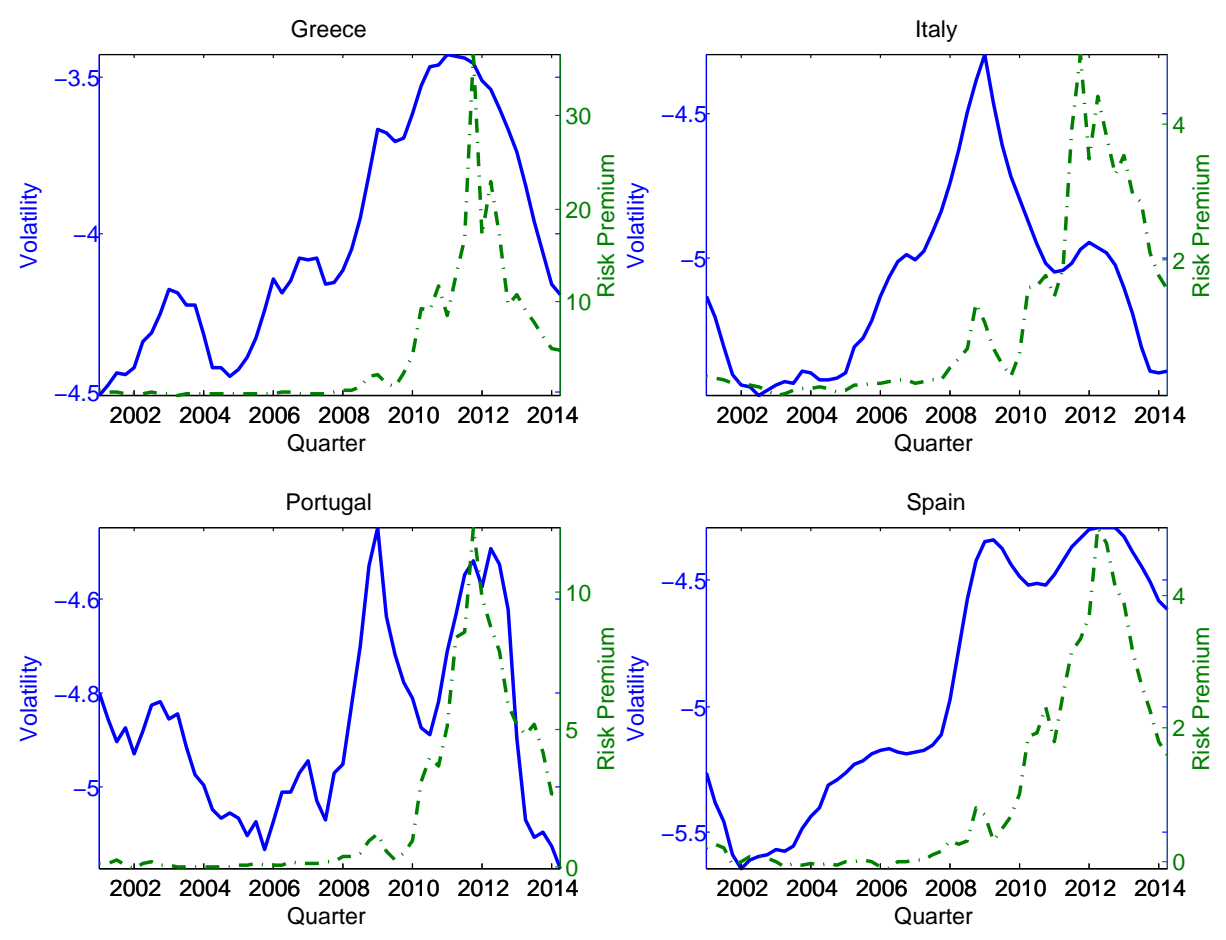

Figure 3: Stochastic volatility and the sovereign risk premium

Note: This figure plots the series for the sovereign risk premium (in dashed line measured in the right axis) and the smoothed estimates of the stochastic volatility implied by the model (in solid lines measured in the left axis).

premium observed in these economies. As seen in the table these measures are highly persistent in all the cases, suggesting that changes in volatility and spreads are likely to exhibit a long lasting effect. A concern that might arise from this evidence is whether the correlations are affected by the fact that we have a short sample and only one crisis, hence, the table also presents correlations for a longer sample. ${ }^{7}$ In this case, we proxy spreads by the "relative asset swap spread", rast, the difference between the real interest rate on long term sovereign bonds and the real return of German long term bonds net of the difference of long term interest rate swaps denominated in domestic currency compared to interest rate swaps in Deutschmark. ${ }^{8}$ This variable allows for sensible pooling of pre-1999 and post-1999 regimes as it removes the exchange rate risk. As seen in the table, the sign and magnitude of correlations is fairly stable regardless the sample which is not surprising given the magnitude of the crisis.

The positive correlation between spreads and volatility is not only contemporaneous. Figure 4 shows correlations for each country between $\sigma_{t+j}$ and spread $_{t}$ for $j=-5: 5$, that is, for leads and lags of

\footnotetext{
${ }^{7}$ In the extended sample Greece sovereign spread series start in 1997Q3, the series for Italy in 1990Q4, Spain 1991Q1 and Portugal 1994Q4.

${ }^{8}$ See Codogno et al. (2003) and Favero et al. (1997) for methodological details and limitations of different approaches.
} 
Table 3: Stylized facts

\begin{tabular}{lcccc}
\hline \hline Moments & Greece & Italy & Portugal & Spain \\
\hline$\rho^{\text {spread }_{t}, \text { spread }}{ }_{t-1}$ & 81.8 & 93.3 & 95.1 & 97.1 \\
& $(11.2)$ & $(12.8)$ & $(13.1)$ & $(13.3)$ \\
$\rho^{\sigma_{t}, \sigma_{t-1}}$ & 98.2 & 97.5 & 91.2 & 99.1 \\
& $(12)$ & $(12.2)$ & $(12.1)$ & $(10.6)$ \\
$\rho^{y_{t}, \text { spread }_{t}}$ & -65.9 & -66.3 & -71.2 & -84.4 \\
& $(8.88)$ & $(9.02)$ & $(9.68)$ & $(11.5)$ \\
$\rho^{\sigma_{t}, \text { spread }_{t}}$ & 71.9 & 18.9 & 53 & 77.2 \\
& $(9.56)$ & $(2.56)$ & $(7.17)$ & $(10.4)$ \\
$\rho^{y_{t}, \text { ras }_{t}}$ & -55 & -37.8 & -52.5 & -57.3 \\
& $(6.61)$ & $(3.88)$ & $(5.9)$ & $(5.91)$ \\
$\rho^{\sigma_{t}, \text { ras }_{t}}$ & 68.4 & 14 & 39.9 & 64.1 \\
& $(8.06)$ & $(1.43)$ & $(4.47)$ & $(6.58)$ \\
\hline
\end{tabular}

Note: In this table, $\rho(i, j)$ denotes the correlation between variable $i$ and $j, y_{t}$ denotes output, $\sigma_{t}$ denotes the $\log$ volatility and spread denotes the sovereign risk premium. Standard errors are in parenthesis. All moments are in percentage terms. The measure of real sovereign spread is the difference between the real interest rate on long term sovereign bonds and the real return of German long term bonds. Raw data on interest rates are the 10 year yield from Datastream, issued in Euros. We assume expected inflation are the same across countries. The last 2 lines present correlations between output and volatility with $\mathrm{ras}_{t}$. $\mathrm{ras}_{t}$ is the 10 year yield euro differential net of the difference of long term interest rate swaps denominated in domestic currency compared to interest rate swaps in Deustche Marks. This variable allows for sensible pooling of pre-1999 and post-1999 regimes as it removes the exchange rate risk.

the log-volatility. As seen in the figure, current volatility is positively correlated with future spreads. The correlation decreases fairly fast for Portugal and Italy, when considering lagged spread and current volatility.

The evidence so far referred to unconditional correlations. It is informative to study the interaction between volatility and spreads during normal times versus recession times. One way of doing this is by estimating the following regression country by country:

$$
\operatorname{spread}_{t}=\beta_{0}+\beta_{1} \sigma_{t}+\beta_{2} D_{t}+\beta_{3}\left(\sigma_{t} \times D_{t}\right)+\hat{\epsilon}_{t},
$$

where, spread $_{t}$ denotes the sovereign spread at period $t, \sigma_{t}$ denotes the log-volatility and $D_{t}$ denotes a 


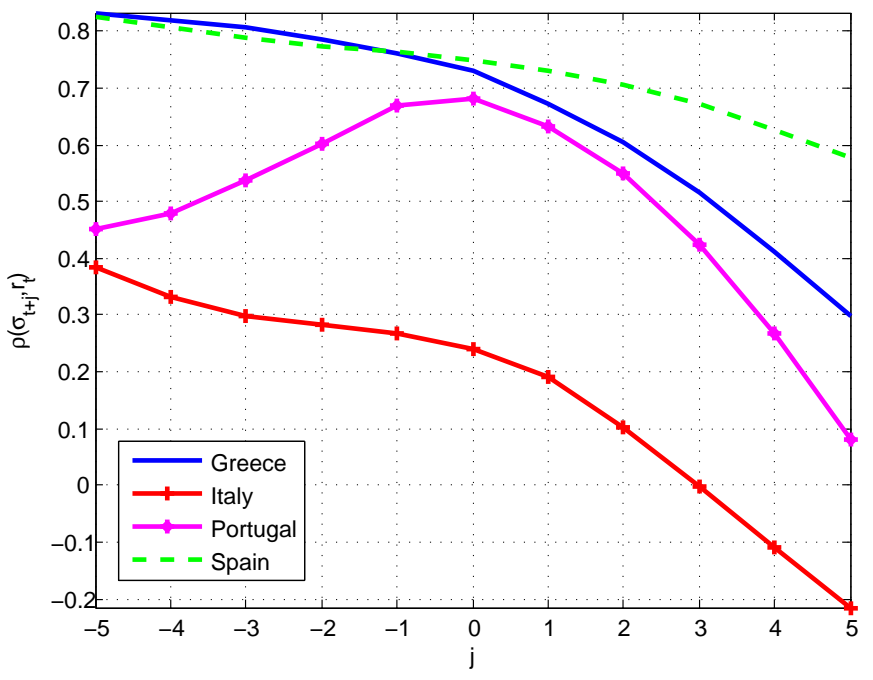

Figure 4: Dynamic correlations between spreads and volatility

Note: dynamic correlations between $\sigma_{t+j}$ and spread $_{t}$ for $j=-5: 5$, specifically $j=0$ stands for the contemporaneous correlation. Spread series from 2001Q1 to 2014Q2

dummy that takes value 1 during recession periods. Table 4 presents the estimates and standard errors of estimating such a regression for each country. The columns "Rec. OECD" and "Rec" display results for 2 alternative recession dates, the first one uses a dummy that take values one for recession periods accordingly to OECD and the second one uses a dummy that takes value of 1 if output growth was negative for 3 consecutive quarters. The column labeled Post-2008 use a dummy that takes values 1 for the crisis period starting in 2008 first quarters until the end of the sample. ${ }^{9}$

As seen in the table, $\beta_{1}$, that captures the unconditional relationship between volatility and spreads, is mostly positive or non-significant. Additionally, during recession periods, the positive relationship between volatility and spreads increases accordingly to $\beta_{3}$, which is also, positive in most of the cases. This implies that the relationship between spreads and volatility is stronger during times of recessions compared to normal times.

In the remainder of the paper, I present the model for endogenous sovereign spreads and use it to study the impact of volatility shocks in savings choice, sovereign risk premium and default probabilities. The model in the following section will be helpful to understand the dynamics behind the positive correlation between sovereign risk premium and volatility. In principle, note that if we read the data through the lenses of a standard RBC model with precautionary savings, as for instance the "debt elastic interest

\footnotetext{
${ }^{9}$ Implementing a time series analysis of sovereign spreads we were unable to reject the hypothesis of unit root. However, it is well known that standard unit root tests fail to reject an unit root in the presence of structural breaks. In our case, introducing dummy variables in the regression allow us to capture such a break.
} 
Table 4: Coefficient Regression

\begin{tabular}{lrrr}
\hline \hline Coefficient & Rec. OECD (St. err.) & Rec. (St. err.) & Post-2008 (St. err.) \\
\hline$\beta_{1}$ (volatility) & $0.05(0.006)$ & $0.002(0.002)$ & $-0.0003(0.0004)$ \\
$\beta_{2}$ (dummy) & $-0.07(0.04)$ & $0.2(0.05)$ & $0.2(0.04)$ \\
$\beta_{3}$ (interaction) & $-0.018(0.01)$ & $0.05(0.01)$ & $0.05(0.01)$ \\
\hline \multicolumn{4}{c}{ Italy } \\
$\beta_{1}$ (volatility) & $-0.0004(0.001)$ & $0.0002(0.001)$ & $0.0006(0.0001)$ \\
$\beta_{2}$ (dummy) & $0.02(0.01)$ & $0.013(0.02)$ & $-0.025(0.007)$ \\
$\beta_{3}$ (interaction) & $0.003(0.002)$ & $0.002(0.004)$ & $-0.006(0.001)$ \\
\hline & Portugal & \\
$\beta_{1}$ (volatility) & $-0.006(0.005)$ & $0.015(0.012)$ & $0.0004(0.0003)$ \\
$\beta_{2}$ (dummy) & $0.20(0.05)$ & $0.09(0.08)$ & $0.07(0.04)$ \\
$\beta_{3}$ (interaction) & $0.04(0.01)$ & $0.02(0.02)$ & $0.012(0.008)$ \\
\hline & Spain & \\
$\beta_{1}$ (volatility) & $0.007(0.0009)$ & $0.002(0.001)$ & $0.00007(0.0002)$ \\
$\beta_{2}$ (dummy) & $-0.005(0.006)$ & $0.04(0.01)$ & $0.07(0.02)$ \\
$\beta_{3}$ (interaction) & $-0.001(0.001)$ & $0.008(0.003)$ & $0.01(0.004)$ \\
\hline
\end{tabular}

Note: Samples from 2001Q1 to 2014Q2. This table presents results for three types of recession dummies. The column labeled "Rec OECD" uses a dummy that takes values one for OECD recession dates, "Rec" uses a dummy that take values one if output growth was negative for 3 consecutive quarters. The column labeled Post-2008 use a dummy that takes values 1 for the crisis period starting in 2008 first quarters until the end of the sample. Standard errors are computed using bootstrap.

rate" model in Schmitt-Grohe and Uribe (2003), an increase in volatility will induce a decrease in the leverage of the economy, or an increase in savings. If this is the case, the sovereign spread would decrease after a volatility shock given that it is positively related to the level of debt. Hence, a standard model with precautionary savings behavior might not be able to capture this fact and hence, might not be appropriate to understand the sovereign spread dynamics.

\section{Endogenous sovereign risk premium}

This paper models the endogenous sovereign spread as in the strategic default literature such as Arellano (2008), Eaton and Gersovitz (1981) and Aguiar and Gopinath (2006). Here, we study an endowment small open economy that trades a homogeneous good with the rest of the world and has access to an 
incomplete international asset market. The government of the small open economy cannot commit to honor its debt and, consequently, she is able repudiate it at any point in time. If the government defaults, it is assumed to lose access to international asset markets and experiences an output loss as long as it is in default. It is assumed, however, it can randomly return to international asset markets. ${ }^{10}$ In this paper, I extend the baseline model by allowing income to follow a stochastic volatility process such as the one estimated in the previous section. Hence, as shown in section 2, the output process is affected by a shock to the level and a shock to the volatility.

\subsection{Model's Setup}

\subsubsection{The domestic economy}

Assume a small open economy populated by a large number of identical households that maximize the expected value of discounted utility given by,

$$
\mathbb{E}_{0} \sum_{t=0}^{\infty} \beta^{t} u\left(c_{t}\right)
$$

Here, $u\left(c_{t}\right)$ denotes the instantaneous utility function, that has a positive first derivative and a negative second derivative. Intuitively, utility increases with consumption but at a decreasing rate. $\beta$ denotes the intertemporal discount factor, that can take values between 0 and 1 , and $c_{t}$ denotes the consumption level of an homogeneous, perishable consumption good in period $t$. Households receive an exogenous stream of output whose logarithm evolves accordingly to the process given by equations (1) and (2) in Section 2.

Assume there is a benevolent government that maximizes households' utility. The government is the only domestic agent that has access to international lending and borrowing markets and can buy international bonds $b^{\prime}$. It is assumed that $b^{\prime}>0$ means that the rest of the world is a debtor to the small open economy whereas $b^{\prime}<0$ means that the domestic economy has a liability with the rest of the world. Given that the government is benevolent and the households have concave utility functions, the government will use bonds issuing to smooth consumption.

Assume the bonds are sold at discount at a price $q\left(b^{\prime}, y, \sigma\right)$. The price of bonds is a function of the current realization of output, the current realization of volatility and the level of bonds chosen by the government in the current period. as often assumed in this literature, the government internalizes the

\footnotetext{
${ }^{10}$ The endowment economy assumption is convenient because of two reasons. First, the output and volatility processes can be directly estimated from available data and second, given that we do not consider capital accumulation, the set of states in simplified. I referred the reader to review Mendoza and Yue (2012) for a model with production, where output is produced using labor and imported inputs.
} 
effect of government debt on the price of debt. This means that the government knows that its behavior in the asset market will affect the equilibrium price at which the bonds are traded.

The key assumption is that the government cannot commit to repay the outstanding debt, that is, the government can default at any time. ${ }^{11}$ If the government choose at any period to repay the outstanding debt, the resource constraint of the economy is given by,

$$
c=y+b-q\left(b^{\prime}, y, \sigma\right) b^{\prime}
$$

Here, accordingly to the notation, $c$ and $b$ denote current consumption and assets, $y$ denotes current output and $\sigma$ denotes current volatility while $b^{\prime}$ denotes the level of assets chosen at the current period that will be predetermined the following period. Note that international lending and borrowing is the only way the government helps households to smooth consumption. Any returns from the international asset market operations are transferred to households using lump sum transfers or taxes.

If the government defaults, the budget constraint reduces to $c=y^{\text {def }}$. Here, $y^{\text {def }}=h(y) \leq y$. With $h(\bullet)$ being increasing in the income shock. We can think about this function as a penalty for defaulting that is increasing in the income realization. Another implication of the previous equation is that when the government defaults, the country is unable to access international asset markets and hence has to consume all its endowment given that it cannot be stored. We will refer to this situation as "autarky". As previous literature, I assume the country can return to asset markets with a probability $\theta$ any period.

\subsubsection{The foreign investors}

The rest of the world is populated by a large number of risk neutral international investors that have access to a risk free asset, that pays risk free interest rate, and also trade the risky asset with the domestic economy. Given that foreign investors are risk neutral, they allocate resources across different assets as long as they break even in expectation. Additionally, given the small open economy assumption any level of funds the domestic economy offers or demands will be traded at the appropriate equilibrium price. Hence, foreign investors' problem is to maximize profits from operating in the international asset markets. Using $\Pi$ to denote the investors profits, we can formalize their problem as follows,

$$
\max \Pi=q b^{\prime}-\frac{1-\delta}{R} b^{\prime} .
$$

\footnotetext{
${ }^{11}$ It is now convenient to switch to the notation commonly used in recursive macroeconomics. Hence, we drop the $t$ sub-indexes and denote next period variables with a'.
} 
Here $R$ is the risk free rate and $\delta$ is the default probability. The equilibrium requires $q=\frac{1-\delta}{R}$. Note that given that $(b, y, \sigma)$ are the states of the economy, and the timing is such that first the government chooses to default or not and then if no default is observed the government chooses how much debt take the current period, the price of debt has to satisfy,

$$
q\left(b^{\prime}(b, y, \sigma), y, \sigma\right)=\frac{1-\delta\left(b^{\prime}(b, y, \sigma), y, \sigma\right)}{R} .
$$

\subsection{Recursive formulation}

It is useful to write the recursive formulation of the problem. The states of the problem are the outstanding level of debt, as long as the government did not default the previous period; the output level; and the realization of the output's volatility; that is $s=(b, y, \sigma)$. Using the previous notation, under no default, the value function for the government is given by,

$$
v^{c}(s)=\max _{b^{\prime}}\left\{u\left(y+b-q\left(b^{\prime}(s), y, \sigma\right) b^{\prime}(s)\right)+\beta \int_{\sigma^{\prime}} \int_{y^{\prime}} v^{o}\left(s^{\prime}\right) f\left(y, y^{\prime}\right) d y^{\prime} g\left(\sigma, \sigma^{\prime}\right) d \sigma^{\prime}\right\} .
$$

Here, we replaced out consumption using the budget constraint under no default and $v^{c}(s)$ stands for the value function under commitment. Also, $f\left(y, y^{\prime}\right)$ denotes the transition function for output levels, $g\left(\sigma, \sigma^{\prime}\right)$ denotes the transition function for volatility levels, and $v^{o}\left(s^{\prime}\right)$ denotes the optimal continuation value, given by,

$$
v^{o}(s)=\max _{c, b^{\prime}}\left\{v^{c}(s), v^{d}(y, \sigma)\right\}
$$

and $v^{d}(y, \sigma)$ denotes the value of default, given by,

$$
v^{d}(y, \sigma)=u\left(y^{d e f}\right)+\beta \int_{\sigma^{\prime}} \int_{y^{\prime}}\left[\theta v^{o}\left(0, y^{\prime}, \sigma^{\prime}\right)+(1-\theta) v^{d}\left(y^{\prime}, \sigma^{\prime}\right)\right] f\left(y, y^{\prime}\right) d y^{\prime} g\left(\sigma, \sigma^{\prime}\right) d \sigma^{\prime} .
$$

Here, $\theta$ is the probability of returning to international asset markets after default. In this way, the recursive formulation indicates that, the government's objective is to maximize the value function of the economy given by $v^{o}\left(b^{\prime}, y^{\prime}, \sigma^{\prime}\right)$ using debt issuance, the default option and consumption. In this framework, we can define a recursive competitive equilibrium as follows.

Definition Recursive Equilibrium. A recursive equilibrium for this small open economy is a set value functions $v^{o}(s), v^{c}(s)$ and $v^{d}(y, \sigma)$, a set of policy functions for the government asset holdings 
$b^{\prime}(s)$, a household's consumption allocation $c(s)$, a default decision $d(s)$, and a pricing function for bonds $q\left(b^{\prime}(s), y, \sigma\right)$, such that:

1. Given $y, \sigma$ and the bond price function $q\left(b^{\prime}(s), y, \sigma\right)$, the government policy function $b^{\prime}(s)$ and default decisions, satisfy the government optimization problem.

2. Given $y, \sigma$, the price of debt $q$, the government policy function $b^{\prime}(s)$ and default decisions, $c(s)$ satisfies the resource constraint.

3. The bond price function $q\left(b^{\prime}(s), y, \sigma\right)$ is consistent with a zero expected profits for international lenders.

To solve for the equilibrium and policy functions we proceed by value function iteration. A detailed description of the algorithm can be found in the Appendix. The next section describes the calibration and steps implemented towards the discretization of the endogenous and exogenous states.

\section{Functional forms, calibration and discretization}

The model is solved using a variant of value function iteration using a grid for assets of 200 nodes. To discretize the exogenous states I use the Rouwenhorst method which has better properties than other methods for highly persistent processes, see Galindev and Lkhagvasuren (2010) and Kopecky and Suen (2010). For the volatility of output I use a grid of 21 nodes. To build the grid for the income process I have to take into account the stochastic volatility that now is represented by the volatility grid. I specify a mean of zero and a correlation as the one in Table 2. However, to specify the standard deviation of the innovation, I first specify the exponent of the first element of the volatility grid, that generates an output grid conditional on the lowest volatility level, and then I construct another grid for output using the second element of the grid for volatility, and so on. For each grid I use 21 nodes. Ultimately the grid for income processes will be one of 21 times 21, each of them associated to a transition probability matrix, as well as one transition probability matrix for the volatility grid. ${ }^{12}$

I assume the following functional forms: the instantaneous utility function is given by

$$
u(c)=\frac{c^{1-\kappa}}{1-\kappa},
$$

\footnotetext{
${ }^{12}$ Note that in the data, I estimate a process in logs, detrended and demeaned. To take it into the model, I discretize these estimated process and given that I have to construct output in levels, I exponentiate the output grid. In this way, I am able to construct income in levels from estimates of log GDP.
} 
where $\kappa$ is the coefficient of risk aversion. Additionally, the output penalty function under default is $y^{\text {def }}=\gamma \bar{y}$, if $y \geq \gamma \bar{y}$ and $y^{\text {def }}=y$ if $y<\gamma \bar{y}$. Here $\bar{y}$ denotes the average output.

I calibrate four versions of the model, one for each of the countries studied in the empirical section. I feed the estimated processes in section 2 for the income and volatility processes in the models and I calibrate the remaining parameters in order to match certain aspects of default episodes during the last two hundred years. As seen in Table 5, these economies experienced several default episodes and suffered long periods in default situation.

Table 5: Default Episodes

\begin{tabular}{lcccc}
\hline \hline Moments & Greece & Italy & Portugal & Spain \\
\hline & & & & \\
Sample & $1826-2010$ & $1800-2010$ & $1800-2010$ & $1800-2010$ \\
External default episodes & 5 & 2 & 4 & 6 \\
Number of years in default & 90 & 15 & 23 & 44 \\
\hline
\end{tabular}

Note: Data is from Reinhart and Rogoff (2010).

I fix $\kappa=2$ as commonly assumed in related studies. I set $\gamma, \beta$ and $\theta$ to match default statistics in Table 5, and to guarantee that during default output is between $10 \%$ to $13 \%$ below trend.

Table 6: Calibration

\begin{tabular}{clrrrr}
\hline \hline Parameter & Description & Greece & Italy & Portugal & Spain \\
\hline & & & & & \\
$\beta$ & Discount factor & 0.92 & 0.94 & 0.95 & 0.93 \\
$\theta$ & Re-entry probability & 0.014 & 0.032 & 0.04 & 0.035 \\
$\gamma$ & Default Penalty & 0.9 & 0.88 & 0.91 & 0.9 \\
$R$ & Risk free rate & 1.007 & 1.007 & 1.007 & 1.007 \\
\hline
\end{tabular}

Table 9 presents a set of non-targeted moments implied by the model and their observed counterparts: the average spread, the volatility of spread averaged across default episodes and simulations, the correlations between spreads and income, spreads and volatility, and the average debt to output ratio. To compute the moments implied by the model I proceed by simulations, I run a 2 million periods simulation, I identify the default episodes and discard the periods in which the economy was in default. Then, for each default episode, I construct a sample of 125 quarters before default for the variables of interest, I compute statistics and average them across all subsamples. The column labeled "Full model" presents the results for the model with level and volatility shocks. As seen in the table, the model is able to 
replicate the main features of the data. ${ }^{13}$

\section{Results}

Macroeconomic uncertainty and the sovereign spread are positively correlated and the relationship between these variables tend to be stronger during times of crisis. It is not obvious the economic reasons behind this fact. To see why, consider the following case: assume a standard small open economy business cycle model with commitment and a sovereign spread that is a positive function of the level of debt, such that if the level of debt increases the sovereign spread increases too. ${ }^{14}$ If we assume that precautionary savings motive holds, which is implicit in a positive third order derivative of the utility function, an increase in the volatility of the economy would imply an increase in savings, which would translate in a drop in sovereign spreads. Hence, this standard model that is in line with conventional wisdom would imply counterfactual dynamics.

As we see, the model with default is able to generate a positive correlation between spreads and volatility as observed in the data. In this section I study the policy functions to understand the economics behind this fact. We are particularly interested on the direct effect of volatility changes on spreads, as well as through the savings decision.

Figure 5 presents some evidence regarding the direct impact. The figure plots the price bond schedule for a low and a mild level of debt issuance as a function of volatility. Each plot keeps constant the level of debt and output is fixed to its average. Hence, this is the sole effect of volatility on the price bond schedule.

As seen in the figure, for each level of debt and output, the economies exhibit a low default probability. This can be seen by the fact that in all the cases, the price of debt is close to $1 / R$. In this case, an increase in volatility is likely to increase default probability. Recall that an increase in volatility raises the probability of a very bad income realization, but also the probability of a very good income realization. Hence, the low default probability for these levels of income and debt implies that the increase in the right tail of the distribution (good realization) tends to matter less than the increase in the left tail of the distribution, thus decreasing the price of debt when volatility is too high. However, this is only a direct effect, there is a second effect coming from the fact that changes in volatility affect savings decisions.

\footnotetext{
${ }^{13}$ The model is not able to generate debt to output ratios as observed in the data, this is a well known problem of these types of models without renegotiation or multiple maturities.

${ }^{14}$ This behavior is in line with conventional wisdom and is captured by one of the most general ways of introducing spreads in small open economy models, "debt elastic interest rate" device.
} 

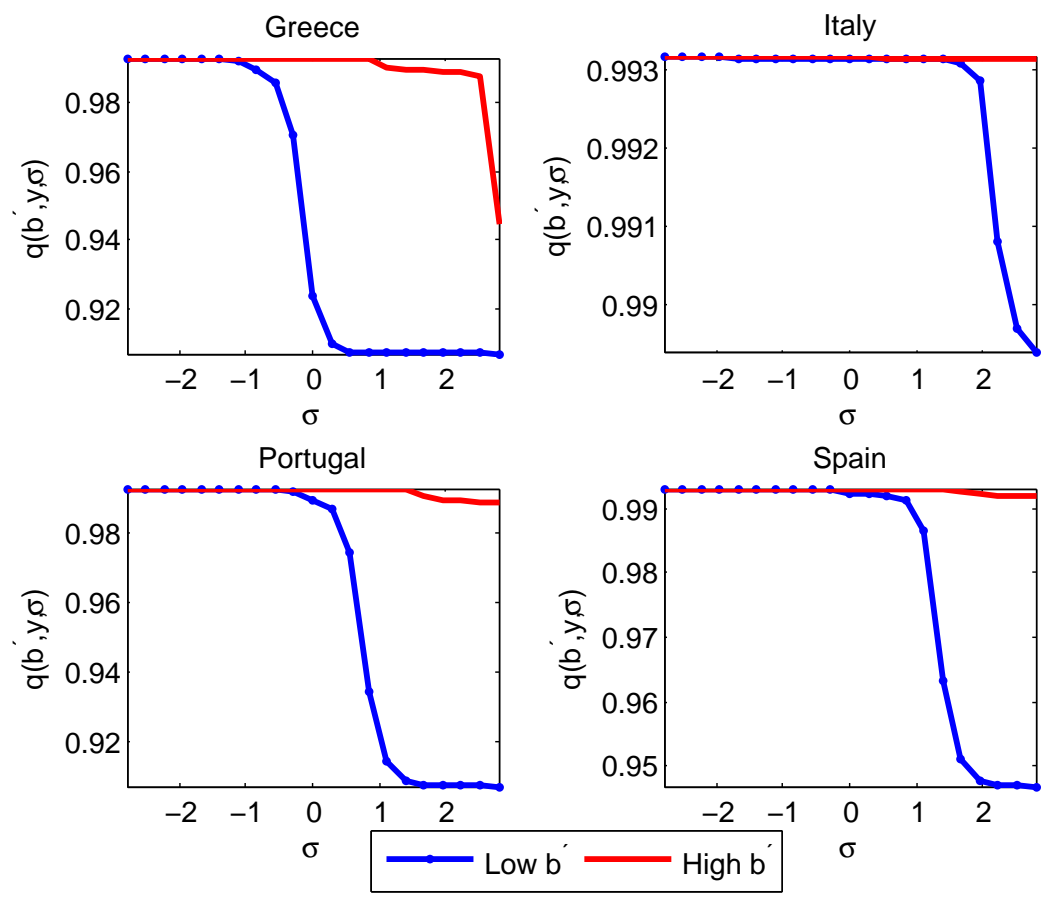

Figure 5: Price bond schedule and volatility

Note: This figure plots the price bond schedule for two levels of debt as a function of volatility. "High $b^{\prime \prime}$ " refers to a situation with high assets (low debt) whereas "Low $b^{\prime \prime}$ " refers to a situation with low assets (high debt).

This can be seen in figure 6 .

The figure plots savings decision conditional on low and high volatility scenarios with the income level fixed at the ergodic level. The red dotted line denotes the high volatility scenario and the blue solid line the low volatility scenario. Notice that the savings curve under high and low volatility crosses each other. When the economy has positive (or mildly) negative savings government saves more under high volatility, suggesting a strong precautionary savings motive. Hence, when the economy is relatively rich, i.e. it has assets or low levels of debt, increases in volatility tend to induce an increase in savings.

On the other hand, when the level of debt is relatively larger, it is possible that the economy save less under high volatility than under low volatility scenarios. This occurs because of the volatility increase and the limited liability induced by default. When the economy is relatively poor, an increase in volatility induces a risk taking behavior that, in this case, assimilates to an increase in debt, making the economy more vulnerable to a negative income shock. The reason why this behavior is optimal is because if the bad scenario occurs, the government is able to exercise the default option whereas if the good scenario 

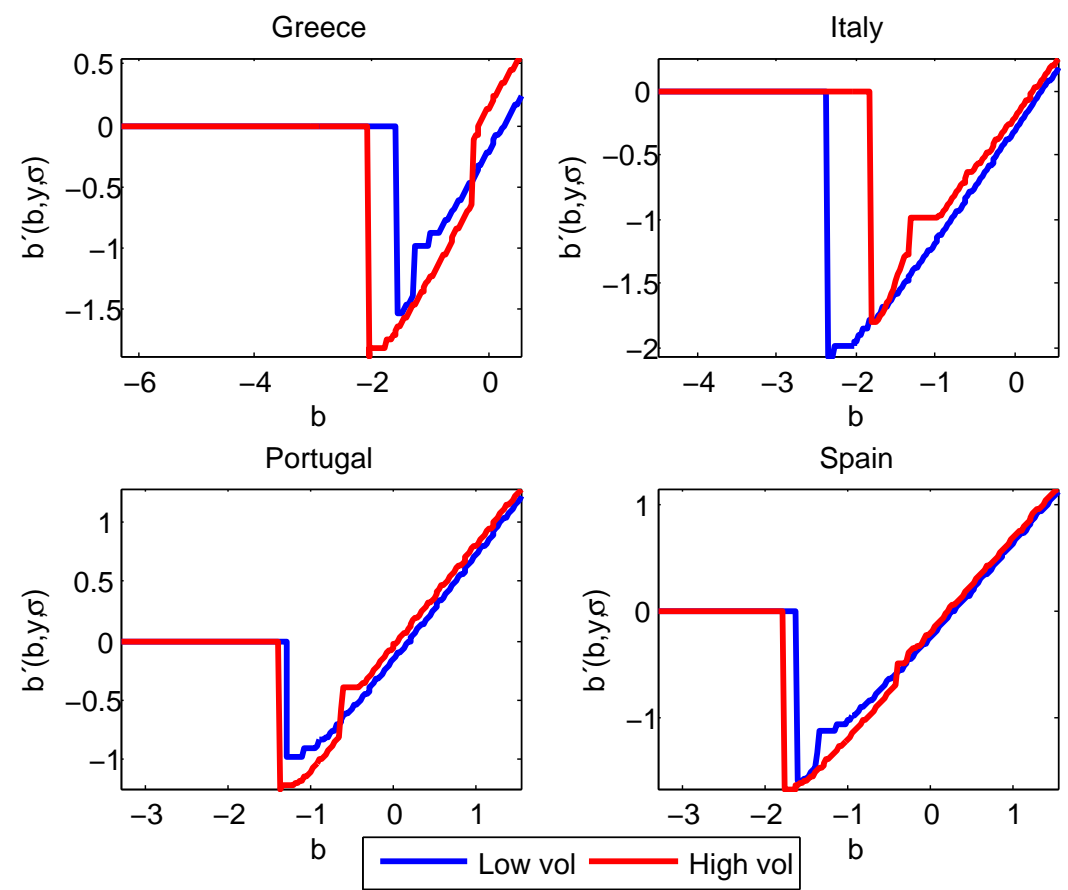

Figure 6: Savings

Note: This figure plots the savings decision for each small open economy. The blue line denotes the low volatility scenario and the red dotted line denotes the high volatility scenario. Low volatility level is the average volatility, while high volatility level is the maximum implied by its grid for each country.

occurs, the economy will be able to repay its debt and even save using international asset markets.

Additionally, in most of the cases, the default region is smaller for the high volatility scenario than for the low volatility scenarios. The economic intuition for this goes as follows, if the economy experiences today a high volatility scenarios, it is likely that this high volatility is present in the future, given that volatility is persistent. Hence, given the option of default tomorrow that bounds the potential losses of a bad income realization, the government cares about the potential gains of a good realization. If the good income shock occurs in the future, the government would like to have access to financial markets in order to save part of the income. This implies that the incentives to default, everything else equal, might be smaller for high volatility economies.

Figure 7 presents the price bond schedule $q\left(b^{\prime}, y, \sigma\right)$ which reflects the default incentives. As seen in the case of savings, here the price bond schedule for high and low volatility also cross, which means that the probability of default can increase or decrease with volatility changes, depending on the level of debt issued. This variable captures the impact of volatility conditional on the economy's desired level of 

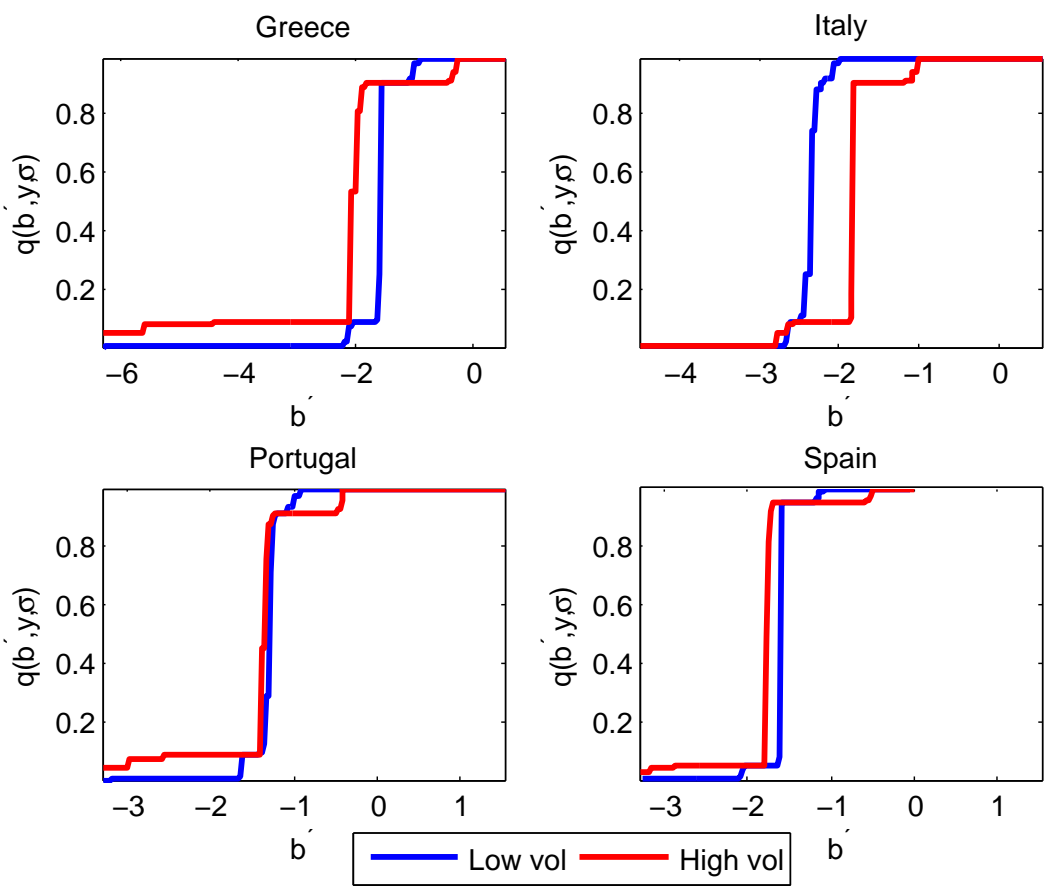

Figure 7: Price bond schedule $\left(q\left(b^{\prime}, y, \sigma\right)\right)$

Note: This figure plots the price bond schedule for each small open economy. The blue line denotes the low volatility scenario and the red dotted line denotes the high volatility scenario. Low volatility level is the average volatility, while high volatility level is the maximum implied by its grid for each country.

debt for the next period. An increase in volatility increases the tails of the income distribution, hence, it increases the probability of good scenarios and the bad scenarios. If the economy is in a region of high default probability, low $q\left(b^{\prime}, y, \sigma\right)$, an increase in volatility can increase $q\left(b^{\prime}, y, \sigma\right)$, meaning that it lowers default probability. The reason is that for any level of $b^{\prime}$, the economy might default with lower probability because if the good scenario occurs, the government want to have access to international asset markets to be able to smooth consumption. For the region in which default probability is low an increase in volatility lowers the price bond schedule. Here an increase in volatility just make your income profile more uncertain, conditional on government's choice of $b^{\prime}$. The dynamics of the equilibrium price of debt, the inverse of the interest rate, is a combination of the price and savings dynamics, as shown in Figure 8.

Note that, as discussed in this section, increases in volatility can have two opposite effects on savings and on the price of debt. If the economy is relatively rich and default probability is small, an increase in volatility is likely to increase asset accumulation, in line with standard precautionary savings motive. This increase in savings (or de-leveraging) contributes to keep a high price of debt and a zero default 

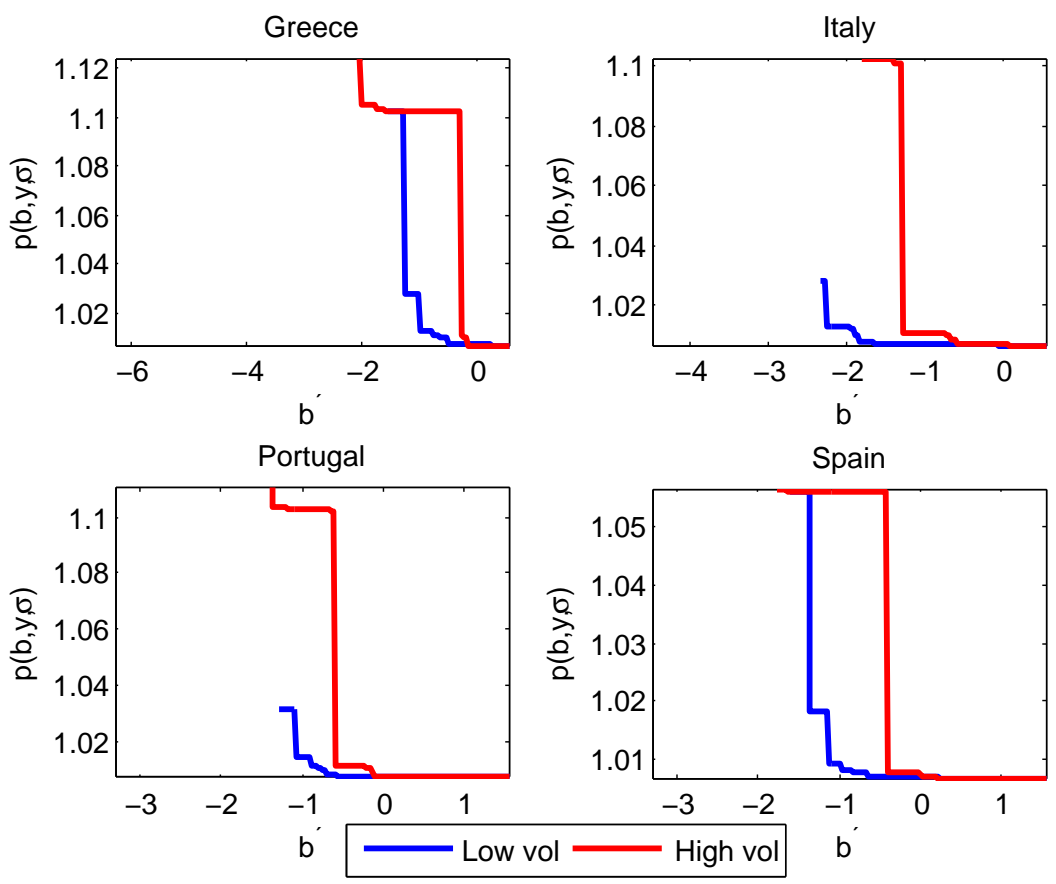

Figure 8: Price bond schedule $\left(q\left(b^{\prime}, y, \sigma\right)\right)$

Note: This figure plots the price bond schedule for each small open economy. The blue line denotes the low volatility scenario and the red dotted line denotes the high volatility scenario. Low volatility level is the average volatility, while high volatility level is the maximum implied by its grid for each country.

probability. On the other hand, if the economy is relatively poor, an increase in volatility can induce an increase in debt accumulation contributing to a higher default probability and to a lower price of debt. Finally, if default probability is close to one, an increase in volatility decreases the price bond schedule because the government would like to have access to asset markets if the good scenario occurs. Hence, for the case of this model, generating a positive correlation between the volatility and the sovereign spread is a quantitative question. In the following section I study variance decomposition and simulation exercises and discuss the quantitative features of the model.

One implication of the economics described above is that the model should generate larger correlation between spreads and volatility during recessions than during expansion. The Table 7 provides evidence in that direction. The table presents moments for each country conditional on the economies endowment being below average (recession) and above average (expansion).

As seen in the table and described above, when output is relatively low, the correlation between volatility and spreads seems to be larger, with larger default incentives, limited liability tends to have 
Table 7: Conditional Non-Targeted Moments

\begin{tabular}{lcccc}
\hline \hline Moments & $\mu($ spread $)$ & $\sigma($ spread $)$ & $\rho($ y, spread $)$ & $\rho($ sv, spread $)$ \\
\hline Recession & 13.3 & 14.7 & -3.7 & 41.3 \\
Expansion & 1.4 & 1.2 & 29.6 & -3.6 \\
& \multicolumn{5}{c}{ Greece } \\
Recession & 1.6 & 2.1 & -41.1 & 40.3 \\
Expansion & 0.5 & 0.7 & 1.7 & 28.6 \\
& & Portugal & \\
Recession & 3.4 & 5.2 & -37.8 & 36 \\
Expansion & 0.8 & 0.8 & -10.4 & 15.4 \\
& & Spain & & \\
Recession & 7.3 & 7.6 & -14.1 & 40.5 \\
Expansion & 0.8 & 2.1 & -0.1 & 4.3 \\
\hline
\end{tabular}

Note: The row "Recession" average moments for realizations conditional on output equal or below average and the row "Expansion" conditions on output above average. All moments are in \%.

a larger impact than precautionary savings motive, which in turn tends to induce increases in spreads when volatility rises. Note that this finding is also in line with the findings in the empirical section of this paper, where we show that during crisis the relationship between spreads and volatility tends to be larger.

A key objective of this section is to study whether volatility shocks can have a quantitatively important effect on the dynamics of the sovereign risk premium. Table 8 compares the default statistics of models when different type of shocks hit the economy. This is a variance decomposition exercise following Fernandez-Villaverde et al. (2011). Given that I solve the model using a non-linear solution method, the interpretation of a variance decomposition exercise is more complicated than the one for linear, or linearly approximated models. In the linear case, the variance of the endogenous variables implies that the variability of endogenous variables computed using one shock at a time will add up to the total variability generated by the model. This is not the case for non-linear models as the shocks might have non-linear interactions. For this reason, the variability under "Level Shocks" and "Volatility Shocks" might not add up to the volatility of the "Full Model" or might even exceed it.

It is important to think on how to understand the variance decomposition exercise. To perform the variance decomposition, I shut down one shock at a time. However stochastic processes do not change (only realization of one of the innovations at a particular time is fixed to 0 ). There are 2 different decomposition exercises. First, to compute the column "Level Shocks" I set to zero the innovations to 
volatility, implying that volatility is fixed to its average. Consequently, the moments under the column "Level Shocks" are those generated only by changes in output level. Note that the policy functions do not change, moreover, agents in the model know "how to respond" to a change in volatility, however, this change in volatility will never happen in the case of only "Level Shocks".

Table 8: Default statistics

\begin{tabular}{|c|c|c|c|c|}
\hline Moments & Data & Full Model & "Level Shocks & "Volatility Shocks* \\
\hline \multicolumn{5}{|c|}{ Greece } \\
\hline Def. epi. / quarters not in def. & 1.3 & 1.2 & 1 & 0.01 \\
\hline Share periods in Def & 49 & 46.7 & 42 & 0.1 \\
\hline Av. Default Duration & 72 & 73.7 & 73 & 90 \\
\hline \multicolumn{5}{|c|}{ Italy } \\
\hline Def. epi. / quarters not in def. & 0.25 & 0.26 & 0.14 & NA \\
\hline Share periods in Def. & 7.1 & 7.6 & 4.1 & NA \\
\hline Av. Default Duration & 30 & 31.2 & 30.3 & NA \\
\hline \multicolumn{5}{|c|}{ Portugal } \\
\hline Def. epi. / quarters not in def. & 0.53 & 0.43 & 0.2 & NA \\
\hline Share periods in Def. & 10.9 & 9.8 & 4.9 & NA \\
\hline Av. Default Duration & 23 & 25 & 24.3 & NA \\
\hline \multicolumn{5}{|c|}{ Spain } \\
\hline Def. epi. / quarters not in def. & 0.9 & 0.8 & 0.57 & 0.0004 \\
\hline Share periods in Def. & 20.9 & 18.1 & 14 & 0.008 \\
\hline Av. Default Duration & 29.3 & 28.2 & 28.6 & 19.6 \\
\hline
\end{tabular}

Note: The column "Data" presents all statistics computed at quarterly frequency. "Def. epi. / quartes not in def." is computed as the number of default episodes divided by the number of quarters the economy is not in default, in percentage terms. Share of periods in default is in percentage terms. Average default duration is in quarters. Original data is at annual frequency, we approximate the quarterly frequencies assuming that if during a particular year the economy is in default, it spends in default the four quarters during that year. The column "Full Model" compute default statistics for the model with level and volatility shocks. The column "Level Shocks" reports moments for the model that only simulates level shocks keeping volatility fixed in its average value. The column "Volatility Shocks" reports moments for the model that only simulates volatility shocks keeping output fixed to its average value. (*) In the cases of Italy and Portugal the model with only volatility shocks was not able to generate default episodes in sample.

To compute the moments under "Volatility Shocks" I proceed in the same way, without changing the stochastic processes. Suppose I simulate the model only with volatility shocks, this means that for instance, in period $t$, I draw one realization for volatility (suppose it is a large realization, implying that volatility is larger than average) and I draw one realization for output which of course in this case it is 0 , implying that output in period $t$ is the average one. Notice that here, the high volatility is persistent and given that stochastic processes do not change, this high volatility is going to have an impact on the 
future, and hence on present choices. If volatility processes are not persistent an increase in volatility will not have any effect, but given that we have persistence, higher volatility affects uncertainty about future income. The key here is persistence and the fact that stochastic processes do not change.

Table 9: Non-Targeted Moments

\begin{tabular}{lcccc}
\hline \hline Moments & Data & Full Model & Level Shocks & Volatility Shocks* \\
\hline \multicolumn{5}{c}{ Greece } \\
$\mu($ spread $)$ & 4.4 & 5.7 & 6.4 & 12.2 \\
$\sigma($ spread $)$ & 7.2 & 10.6 & 11.4 & 15.9 \\
$B / Y$ & $-106.3^{* *}$ & -34.3 & -33.6 & -24.4 \\
$\rho(y$, spread $)$ & -65.9 & -36.2 & -42.7 & - \\
$\rho($ sv, spread $)$ & 71.9 & 12.5 & - & 56 \\
\hline \multicolumn{5}{c}{ Italy } \\
$\mu($ spread $)$ & 1.1 & 1.15 & 0.98 & 0.92 \\
$\sigma($ spread $)$ & 1.3 & 1.75 & 1.1 & 0.8 \\
$B / Y$ & $-51^{* *}$ & -46 & -47.8 & -45.3 \\
$\rho(y$, spread $)$ & -66.3 & -38.8 & -42.1 & - \\
$\rho($ sv, spread $)$ & 18.9 & 30.3 & - & 68.5 \\
\hline & \multicolumn{5}{c}{ Portugal } \\
$\mu($ spread $)$ & 2 & 2 & 1.9 & 1.5 \\
$\sigma($ spread $)$ & 3.1 & 3.6 & 2.2 & 0.9 \\
$B / Y$ & $-53^{* *}$ & -22 & -22.9 & -20.2 \\
$\rho(y$, spread $)$ & -84.4 & -38.8 & -48.9 & - \\
$\rho($ sv, spread $)$ & 77 & 23.5 & - & 69.4 \\
\hline \multicolumn{5}{c}{ Spain } \\
$\mu($ spread $)$ & 1 & 3.7 & 4.3 & 7.9 \\
$\sigma($ spread $)$ & 1.5 & 6 & 6.3 & 7.1 \\
$B /$ Y & $-62^{* *}$ & -37.1 & -36.7 & -30.2 \\
$\rho(y$, spread $)$ & -62 & -37.5 & -41.9 & - \\
$\rho($ sv, spread $)$ & 80 & 17.9 & - & 59.6 \\
\hline
\end{tabular}

Note: The column "Full Model" compute statistics for the model with level and volatility shocks. The column "Level Shocks" reports moments for the model that only simulates level shocks keeping volatility fixed in its average value. The column "Volatility Shocks" reports moments for the model that only simulates volatility shocks keeping output fixed to its average value. $(*)$ In the cases of Italy and Portugal the model with only volatility shocks was not able to generate default episodes in sample, for these cases, we show unconditional statistics. Computed using sample sizes of 125 quarters. (**) Net external debt position as \% of GDP (Eurostat). All moments are in \%.

As seen in the table, the default frequency decreases if we remove volatility shocks. For instance, default frequency for Spain goes from $0.8 \%$ to $0.57 \%$ without volatility shocks and similar findings are observed for the rest of the countries. In all the cases, the interaction between level and volatility shocks induce an increase in frequency of default. Notice that this suggests that the mechanism described in the previous section is quantitatively important, volatility shocks increase the probability of default. Instead, a model with only volatility shocks is unlikely to generate default episodes. In the cases of 
Greece and Spain, it does it with a frequency of $0.01 \%$ while for Italy and Portugal, the models are not able to generate default episodes in simulations. Table 9 presents the average, standard deviations and correlations of key variables.

As seen in the table, volatility shocks can actually affect first and second moments. Shutting down volatility shocks affect average and volatility of spreads for Italy and Portugal, but not really for the cases of Greece and Spain. Instead, volatility shocks alone can generate substantial variation in the spreads in all the cases. I consider next two extensions calibrated to Spanish data.

\section{Extensions}

The extensions studied in this section intends to clarify the role of lenders' pricing in the spread dynamics and the possibility of feedback effects from spread changes and spread volatility into aggregate volatility. I study the first point by assuming risk averse investors, and the second point by designing a version of the model with endogenous labor.

\subsection{Risk averse lenders}

Volatility changes affect the desire to save/borrow but also affect pricing schemes of the lenders, hence, considering the case of risk averse lenders might give rise to interesting dynamics. As an extension, I consider the case of risk averse lenders in a simplest form, by modeling a reduced form of their stochastic discount factor. ${ }^{15}$

A risk averse investor will price defaultable debt taking into account the co-movement of its return with its stochastic discount factor. The first question in the case of European economies, is who can be considered the representative investor in the data. Figure 9 plots the stochastic discount factors computed assuming log utility functions for a representative investor in Spain, Germany, US or the Euro Area. ${ }^{16}$

As seen in the figure, different stochastic discount factors have a high co movement with the Spanish discount factor, where the ones computed using German, US and Spanish data are the more volatile. This information is summarized in the following table,

Following Arellano (2008), we proxy the stochastic discount factor as $m_{t+1}=R^{-1}-\lambda \epsilon_{t+1}^{y}$. Here $\lambda=0.13$ regulates the volatility of the stochastic discount factor. I fix it such that the model's SDF maps the average volatility in Table 10, I recalibrate $\gamma=0.93$ such that default frequency is in line with

\footnotetext{
${ }^{15}$ I follow the setup as in Arellano (2008) but for a more microfundated approach see Lizarazo (2012).

${ }^{16}$ That is, using the growth rate of consumption in each of the locations, the SDF would be given by $M_{t+1}=\beta \frac{C_{t}}{C_{t+1}}$.
} 


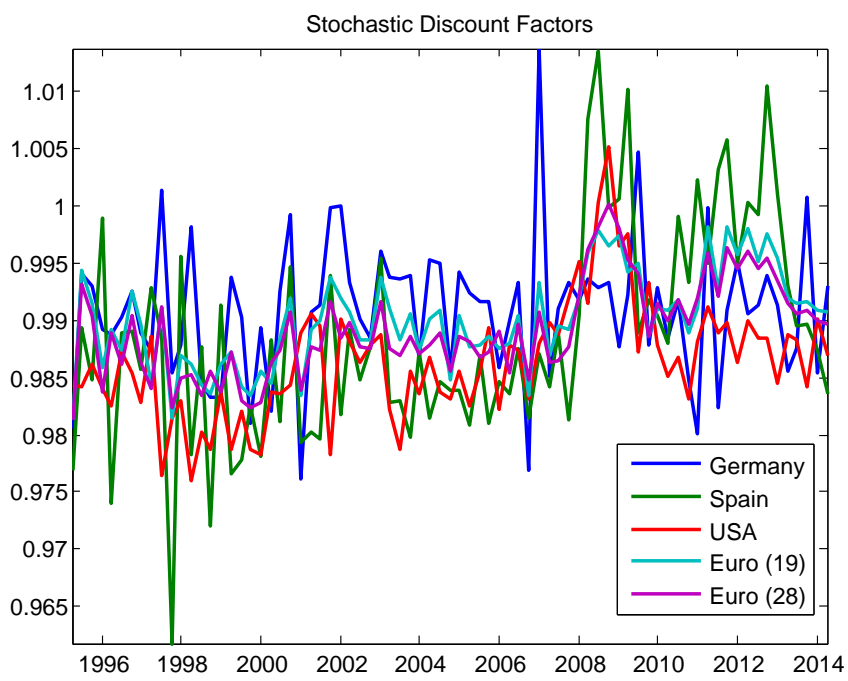

Figure 9: Stochastic Discount Factors

Note: stochastic discount factors using log utility for Germany, USA, Spain, Euro 19 countries, Euro 28 countries.

Table 10: Stochastic Discount Factors

\begin{tabular}{lrr}
\hline \hline Investors & Corr. with/Spain SDF & Volatility \\
\hline & & \\
Germany & 12 & 0.6 \\
Spain & - & 0.9 \\
USA & 53 & 0.5 \\
Euro (19) & 71 & 0.4 \\
Euro (28) & 73 & 0.4 \\
\hline Average & 52 & 0.6 \\
\hline
\end{tabular}

Note: Volatilities and correlations in percentage terms.

the data (for this calibration it generates a default frequency of about 1\%). Using 200 grid points for the debt grid, savings policy, the price bond schedule as a function of debt with risk aversion under high and low volatility and the price bond schedule as a function of volatility for high and low debt are shown in figure 10.

As seen in the figure, the degree of lenders risk aversion such that it matches the average stochastic discount factor in the data does not modify the main features of the savings function for the case of Spain, once the default frequency is matched. However, the price of debt decrease faster as volatility increases, suggesting that in this case, an extra compensation to the lender takes place. The main findings seem to 

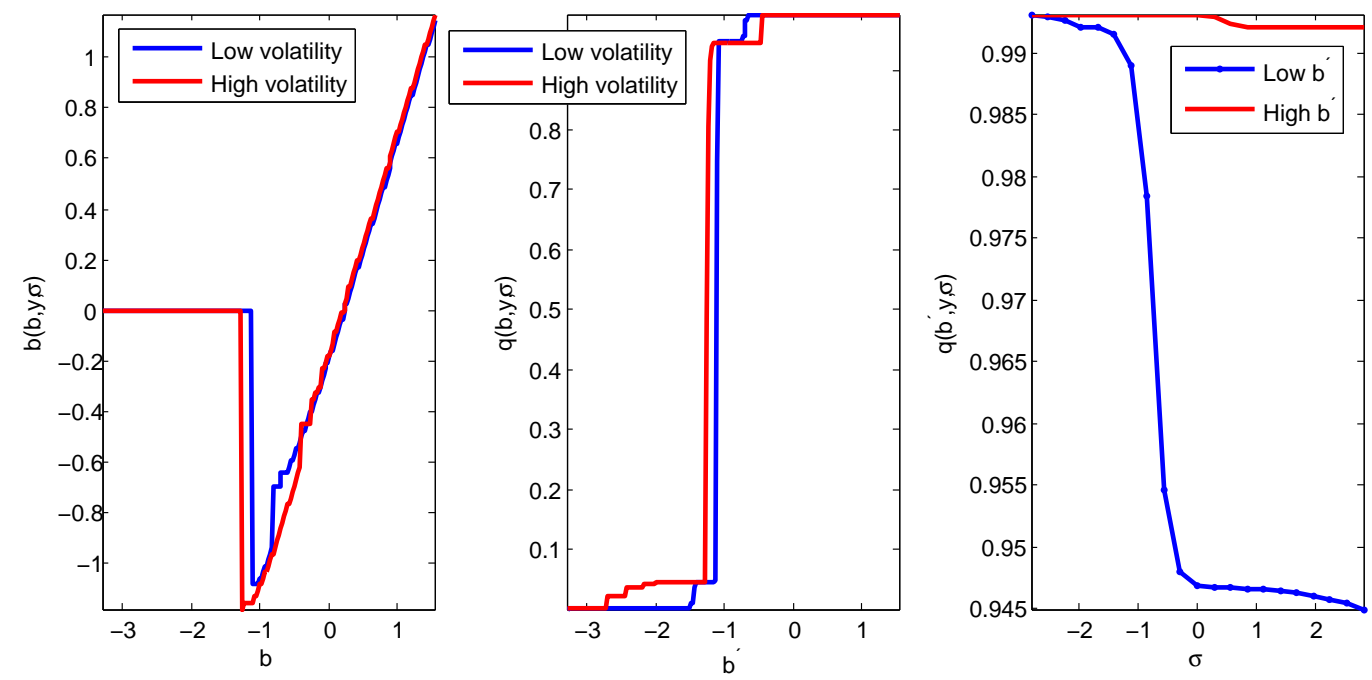

Figure 10: Savings function and the price bond schedule

Note: From left to right, the first figure shows savings function for the model calibrated to Spain with risk averse lenders assuming as a function of the asset position for low (blue) and high (red) volatility. The second figure plots the price bond schedule for low and high volatility- The third picture plots the price bond schedule for high and low asset position as a function of the volatility level ("high $b$ "" refers to a situation with high assets (low debt) whereas "low $b$ " refers to a situation with low assets (high debt)). In all the cases, income is fixed at its average level.

hold under risk averse lenders.

\subsection{Production Economy}

As a second extension, I consider the production economy. This variant is particularly important given the potential feedback effects in the relationship between volatility and spreads. When considered a model with endogenous output, we allow for feedback effects from spreads to output through equilibrium labor. ${ }^{17}$

Suppose the economy is populated by firms that are owned by households and produce with a CobbDouglas technology. Firms maximize profits, and pay wages to the workers and distribute profits to households. Assume households supply labor and their utility function is of a GHH form as in Greenwood et al. (1988)

$$
U(c, h)=\frac{1}{1-\kappa}\left(c-\psi \frac{h^{\omega}}{\omega}\right)^{1-\kappa},
$$

\footnotetext{
${ }^{17}$ In this section, we are not going to develop a theory of endogenous time-varying volatility. Instead, I will compute and simulate endogenous output using the model and I am going to consider output as an observable which will be used to estimate a stochastic volatility process as the one estimated in Section 2.
} 
with a budget constraint for periods in which the economy has access to asset markets given by

$$
c=w h+\Pi+T
$$

where $w$ are wages, $\Pi$ denote firms profits and $T$ are government transfers from operating in international asset markets, $T=b-q\left(b^{\prime}, y, \sigma\right) b^{\prime}$.

Given GHH utility, labor supply does not depend on the price of debt. Consider then an extension where firms have to finance a fraction $\eta$ of the wage bill using working capital such that firms profits are, ${ }^{18}$

$$
\Pi=A h^{1-\alpha}-w h-\left(\frac{1}{q\left(b^{\prime}, y, \sigma\right)}-1\right) \eta w h
$$

Optimality condition for this firm is given by

$$
w=\frac{A(1-\alpha) h^{-\alpha}}{1+\left(\frac{1}{q\left(b^{\prime}, y, \sigma\right)}-1\right) \eta}
$$

In turn, the planner faces the following resource constraint during periods with debt repayment,

$$
c=A h^{1-\alpha}\left(\frac{(1-\alpha)}{1+\eta\left(\frac{1}{q\left(b^{\prime}, y, \sigma\right)}-1\right)}+\alpha\right)+b-q\left(b^{\prime}, y, \sigma\right) b^{\prime},
$$

and, when in default

$$
c=\tilde{A}^{\text {def }} h^{1-\alpha}\left(\frac{(1-\alpha)}{1+\eta\left(\frac{1}{q\left(b^{\prime}, y, \sigma\right)}-1\right)}+\alpha\right) .
$$

Here $\tilde{R}$ is a domestic autarky rate and $\tilde{A}^{\text {def }}$ is the productivity level under autarky that assumes an increasing penalty cost as in the case of the endowment economy. It is important to put up front 2 limitations of this setup. The first one is the straight assumption that the working capital constraint pays the same return as the implicit return of the sovereign debt. In Pancrazi et al. (2014) it is shown that a decentralized version of this model with private banking and liquidity production established a tight link between the private domestic interest rate at which firms finance a working capital constraint and the sovereign rate. The second limitation is that during default, the working capital constraint pays a fixed domestic interest rate called $\tilde{R}$. Also in Pancrazi et al. (2014) we show that a decentralized banking sector can generate the same expressions with a time-varying domestic autarky interest rate.

\footnotetext{
${ }^{18}$ For a similar market decentralization, see Uribe and Yue (2006). In a version of default models, see Pancrazi et al. (2014).
} 
It is important also to highlight that the first limitation of this setup has no practical consequences to the analysis, whereas the second limitation affects default frequency but not statistical moments during non-default periods, which are the moments we are interested in.

A first step is to estimate a TFP process with stochastic volatility. I use the Solow Residual in $y=A h^{1-\alpha}$ with $\alpha=0.3$. $h$ denotes hours and is measured as total hours worked from "Base de Datos del Modelo REMS" (October 2014), and the TFP is log-linearly detrended. Prior distributions are shown in Table 11.

Table 11: Prior Distributions for the Solow Residual SV process

\begin{tabular}{cr}
\hline \hline Parameter & Distributions \\
\hline$\rho$ & $N(0.95,0.035)$ \\
{$\left[\begin{array}{r}\bar{\sigma}\left(1-\rho^{\sigma}\right) \\
\rho^{\sigma}\end{array}\right]$} & $N\left(\left[\begin{array}{r}-0.25 \\
0.95\end{array}\right],\left[\begin{array}{rr}0.3 & 0.04 \\
0.04 & 0.008\end{array}\right]\right)$ \\
$\eta$ & $\mathrm{IG}(3,0.6)$ \\
\hline \hline
\end{tabular}

Note: $N(x, y)$ denotes a Normal distribution with mean $x$ standard deviation $y$. The priors for autocorrelation coefficients are truncated normal in the interval $(0,0.995) . I G(x, y)$ denotes an Inverse Gamma distribution with degrees of freedom $x$ and scale matrix $y$.

Table 12 shows the posterior medians and credible sets for a SV model of the Solow residual $A$.

Table 12: Posterior estimates for Spain

\begin{tabular}{crrr}
\hline \hline Parameter & Posterior Median & 16th Percentile & 84th Percentile \\
\hline $\bar{\sigma}$ & -5.1 & -5.4 & -4.8 \\
$\rho$ & 0.97 & 0.95 & 0.98 \\
$\rho^{\sigma}$ & 0.85 & 0.79 & 0.91 \\
$\eta$ & 0.51 & 0.42 & 0.63 \\
\hline
\end{tabular}

Note: We make 25,000 draws from a Gibbs Sampler and use the last half in order to compute posterior medians and 16th and 84th percentiles.

For the remainder of the parameters, I keep the baseline parametrization for Spain and I set $\psi=1$ and $\omega=1.455$, which implies a Frisch elasticity of 2.2 that is standard in the small open economy literature. For the case with working capital constraints, I assume $\eta=1$ and $\bar{R}=1.15$.

First of all, it is important to point out that the main findings of the endowment model do not change when considering endogenous output. The existence of endogenous labor supply reduces substantially default probability but the policy functions and price bond schedules have the same properties as in 
the baseline case. In particular, the savings function in Figure 11 show a similar interaction between precautionary savings and limited liability.
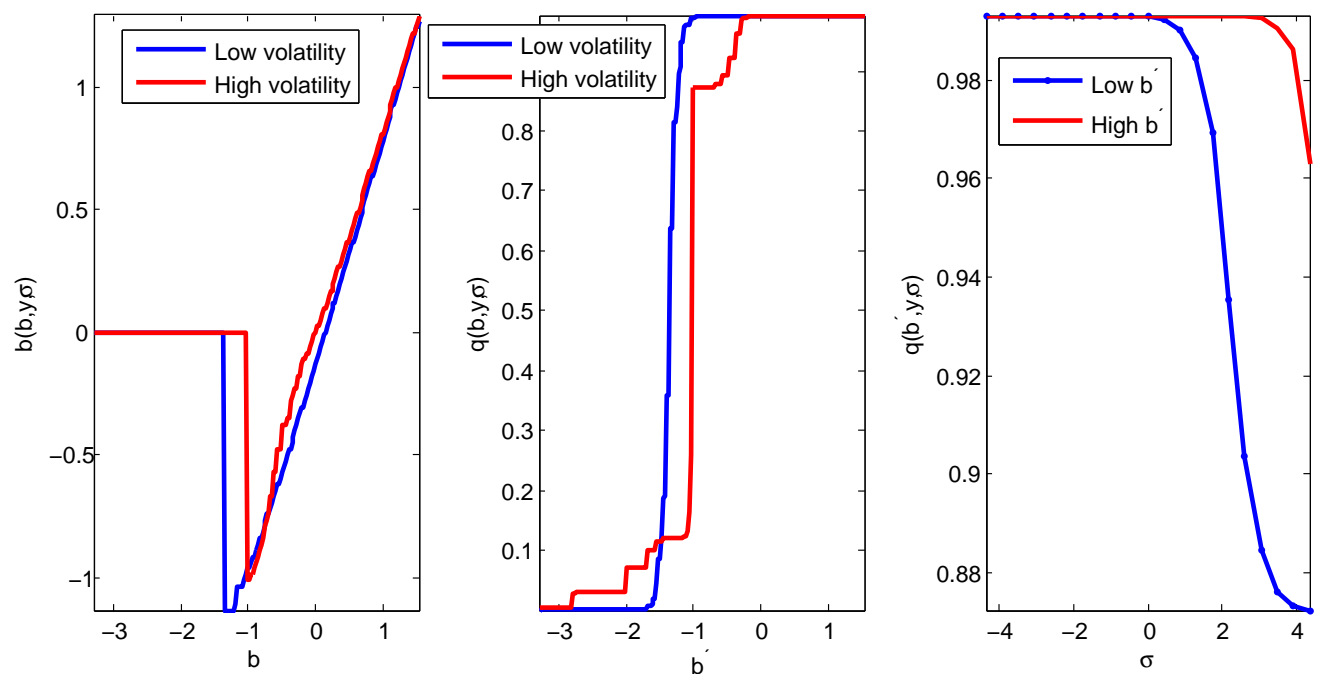

Figure 11: Production economy with working capital constraint

Note: From left to right, the first figure shows savings function for the model calibrated to Spain with risk averse lenders assuming as a function of the asset position for low (blue) and high (red) volatility. The second figure plots the price bond schedule for low and high volatility- The third picture plots the price bond schedule for high and low asset position as a function of the volatility level ("high $b^{\prime \prime}$ " refers to a situation with high assets (low debt) whereas "low $b^{\prime}$ " refers to a situation with low assets (high debt)). In all the cases, income is fixed at its average level.

The objective of this section is to study the potential feedback effects of endogenous output to the aggregate volatility of the system and to a measure of time varying volatility. To do this I proceed as follows. First, I solve the model without a working capital constraint, here debt or default decision do not affect output or output volatility because they do not affect labor supply, this is going to be the benchmark specification. Then I solve a version of the model with working capital constraint. Using these 2 models, I simulate output series of 125 periods each. I estimate stochastic volatility model for each series and I inquire whether the effects of spreads on labor decisions augment or not the estimated output volatility. In this way, we can identify some feedback effects from spreads to output volatility. Notice that I do not assume a parametric structure for output volatility in the model, instead, I use simulated data to estimate it as if it where real data. This is an important assumption because it allows me to proceed in an agnostic way regarding the microfundation of stochastic volatility, for which there is yet no widely accepted theory. 
Figure 12 presents histograms containing the mean of the volatility series and the standard deviation of volatility series, estimated using the output simulated series for the model without working capital constraint (right block) and the model with working capital constraint (left block).

Figure 12: Implied SV with and without working capital constraints
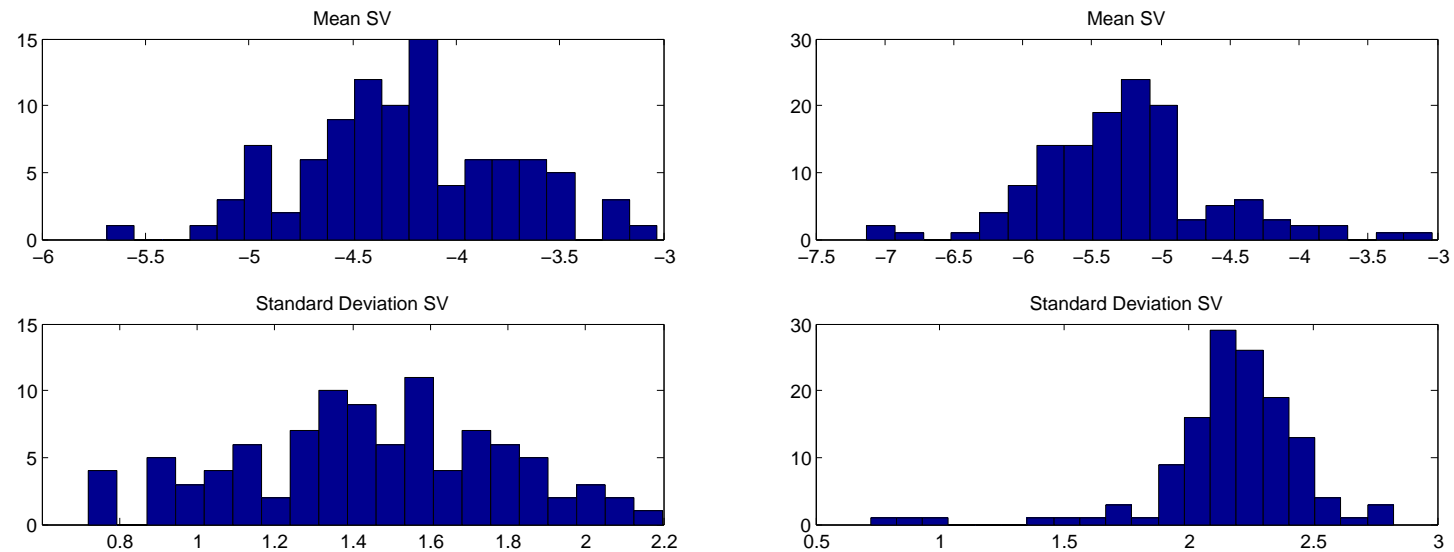

Note: The left figure block refers to the model with working capital constraints (97 samples) while the right figure block to the model without working capital constraints (130 samples). Each estimation is performed using the last half of 2500 draws from the Gibbs Sampler.

As discussed before, the model with working capital constraints is able to capture a feedback effect from spreads to the implied volatility of the model. In this case, given that changes in spread affects equilibrium labor, this ends up translating in an average higher income volatility as compared to the model in which we have labor but this feedback effect is absent as a consequence of GHH preferences and no working capital constraints.

\section{Conclusion}

This paper provides some novel insights for the understanding of savings and consumption decision under uncertainty and the role and quantitative implications of volatility changes on sovereign spreads and savings with endogenous default. Specifically, the setup in this paper helps understanding the state dependent impact of volatility on the savings decision, which is not observed in standard RBC models for small open economies.

I start by studying sovereign spreads and the volatility of GDP for Spain, Italy, Portugal and Greece. 
I find a strong and significant positive correlation between the sovereign spread and the volatility of GDP. Endogenous default models with stochastic volatility is able to capture this fact. Moreover, a variance decomposition exercise shows that volatility shocks alone can generate substantial share of the sovereign spreads variability. I show that an increase in the volatility of output has asymmetric impact on endogenous variables depending on the income and level of debt. In a state of high income and high asset accumulation, an increase in volatility induces precautionary savings. Conversely, an increase in the volatility of output when debt is high or income is low, can actually have a negative effect on savings. The rationality behind these findings are as follows: when the economy is relatively rich and default probability is zero, the economy behaves in a similar way to an economy without default option and the precautionary savings motive induces an increase in savings after a volatility shock. On the other hand, when the economy is relatively poor and default probability is large, the government realizes that high volatility increases the probability of high income realizations and, if this happens, the economy would like to experience a high consumption increase in the future; however, an increase in volatility also increases the probability of a low income realization, in which case the economy would be able to ameliorate the consumption drop by defaulting. Hence, depending on the size of the increase in volatility, and how large default incentives are, the government might actually increase debt today in order to take advantage of the probability of a high output realization in the future, given that the limited liability implies that the economy will not face all the losses of a very bad income realization.

In sum, an increase in the volatility of income can induce an increase in default probability and subsequently, it might lead to a lower price of debt and a higher sovereign spread. The mechanism described in this paper rationalizes the positive correlation between sovereign spreads and volatility observed in the data.

\section{References}

Aguiar, M., Gopinath, G., 2006. Defaultable debt, interest rates and the current account. Journal of International Economics 69, 64-83.

Arellano, C., 2008. Default risk and income fluctuations in emerging economies. The American Economic Review 98, 690-712.

Bloom, N., 2009. The impact of uncertainty shocks. Econometrica 77, 623-685. 
Bloom, N., Bond, S., Van Reenen, J., 2007. Uncertainty and investment dynamics. Review of Economic Studies 74, 391-415.

Cantor, R., Packer, F., 1996. Determinants and impact of sovereign credit ratings. Economic Policy Review , 37-53.

Cline, W., 2004. International debt reexamined. Peterson Institute Press: All Books .

Codogno, L., Favero, C., Missale, A., 2003. Yield spreads on emu government bonds. Economic Policy $18,503-532$.

Cuadra, G., Sapriza, H., 2008. Sovereign default, interest rates and political uncertainty in emerging markets. Journal of International Economics 76, 78-88.

Eaton, J., Gersovitz, M., 1981. Debt with potential repudiation: Theoretical and empirical analysis. The Review of Economic Studies 48, 289-309.

Eichengreen, B., Mody, A., 2000. What explains changing spreads on emerging market debt?, in: Capital Flows and the Emerging Economies: Theory, Evidence, and Controversies. National Bureau of Economic Research, Inc. NBER Chapters, pp. 107-136.

Favero, C.A., Giavazzi, F., Spaventa, L., 1997. High yields: The spread on german interest rates*. The Economic Journal 107, 956-985.

Fernandez-Villaverde, J., Guerron-Quintana, P., Rubio-Ramirez, J.F., Uribe, M., 2011. Risk matters: The real effects of volatility shocks. American Economic Review 101, 2530-61.

Galindev, R., Lkhagvasuren, D., 2010. Discretization of highly persistent correlated ar (1) shocks. Journal of Economic Dynamics and Control 34, 1260-1276.

Garcia Cicco, J., Heresi, R., Naudon, A., 2012. The real effects of global risk shocks in small open economies .

Greenwood, J., Hercowitz, Z., Huffman, G., 1988. Investment, capacity utilization, and the real business cycle. The American Economic Review 78, 402-417.

Gruss, B., Mertens, K., 2009. Regime Switching Interest Rates and Fluctuations in Emerging Markets. Economics Working Papers ECO2009/22. European University Institute. 
Justiniano, A., Primiceri, G., 2008. The time-varying volatility of macroeconomic fluctuations. The American Economic Review 98, 604-641.

Kim, S., Shephard, N., Chib, S., 1998. Stochastic volatility: likelihood inference and comparison with arch models. The Review of Economic Studies 65, 361-393.

Kopecky, K.A., Suen, R.M., 2010. Finite state markov-chain approximations to highly persistent processes. Review of Economic Dynamics 13, 701-714.

Lizarazo, S.V., 2012. Default risk and risk averse international investors. Journal of International Economics Forthcoming.

Longstaff, F., Pan, J., Pedersen, L., Singleton, K., 2011. How sovereign is sovereign credit risk? American Economic Journal: Macroeconomics 3, 75-103.

Mendoza, E., Yue, V., 2012. A general equilibrium model of sovereign default and business cycles. The Quarterly Journal of Economics 127, 889-946.

Pancrazi, R., Seoane, H., Vukotic, M., 2014. Sovereign Risk, Private Credit, and Stabilization Policies. Technical Report. mimeo.

Reinhart, C.M., Rogoff, K.S., 2010. From financial crash to debt crisis. American Economic Review 101, $1676-1706$.

Schmitt-Grohe, S., Uribe, M., 2003. Closing small open economy models. Journal of International Economics 61, 163-185.

Uribe, M., Yue, V., 2006. Country spreads and emerging countries: Who drives whom? Journal of International Economics 69, 6-36.

Yue, V., 2010. Sovereign default and debt renegotiation. Journal of International Economics 80, $176-187$. 